Derechos reservados de El Colegio de Sonora, ISSN 1870-3925

\title{
Etnicidad y salud. Estado del arte y referentes del noroeste de México*
}

\author{
Jesús Armando Haro**
}

Resumen: El propósito central de este ensayo es mostrar la necesidad de ampliar nuestros referentes teóricos y metodológicos en el estudio de la relación entre etnicidad y salud, a partir de la premisa de particularizar el análisis epidemiológico mediante la integración de datos cuantitativos y cualitativos, en concordancia con el enfoque de la epidemiología sociocultural. Para ello, el trabajo aborda inicialmente el estado del arte para proponer la conveniencia de distinguir entre tres ámbitos relacionados: el genotipo, el fenotipo y la etnicidad. Enseguida se presentan algunos resultados selectos de investigación que pretenden señalar ciertas diferencias relevantes entre los pueblos indígenas del país y los de la región noroeste de México. Finalmente, se amplían algunas reflexiones emanadas de este ejercicio a modo de conclusiones y se examina la pertinencia de la epidemiología sociocultural como marco analítico para aplicarse en particular al estudio de la salud en poblaciones étnicamente diferenciadas.

Palabras clave: etnicidad y salud, epidemiología sociocultural, salud indígena en el noroeste de México.

\footnotetext{
* Agradezco la colaboración de José Luis Figueroa, Macrina Restor y Blanca Zepeda en la obtención de datos para este documento. Mi agradecimiento es también para el Seminario Permanente de Antropología Médica de CIESAS, donde recibí comentarios muy precisos para la re-elaboración del primer apartado de este artículo. Asimismo, para María Teresa Valdivia Dounce y Elizabeth Cartwright, quienes me hicieron llegar valiosas sugerencias de contenido y forma.

** Profesor-investigador del Centro de Estudios en Salud y Sociedad en El Colegio de Sonora. Correspondencia: Avenida Obregón 54, Hermosillo, México 83000. Correo electrónico: aharo@colson. edu.mx
} 
Abstract: The main purpose of this essay is to illustrate the need to extend our theoretical and methodological frames in the study of ethnicity and health, deriving a specific case from the general in the epidemiological analysis by means of integrating cuantitative and qualitative data. With this aim, this paper first approaches the state of the art in the field of ethnicity and health, and proposes the convenience of distinguishing between three related fields: genotype, phenotype and ethnicity. Then some selected research results are presented in order to prove certain differences between the indigenous people of Mexico and those from the country's northwestern region. Finally, some reflections are elaborated from this exercise as conclusions, discussing the appropriateness of sociocultural epidemiology as analytical frame in the study of health of ethnically differentiated populations.

Key words: ethnicity and health, sociocultural epidemiology, indigenous health in northwestern Mexico.

\section{Introducción}

Una causa reconocida de desigualdades e inequidades en el campo de la salud es la referida a la condición étnico-racial, un hecho ampliamente aceptado e investigado por la biomedicina y la epidemiología, así como por las ciencias sociales relacionadas con la salud, documentándose en las últimas décadas la relevancia del tema por parte de organismos internacionales, gobiernos nacionales, movimientos indígenas y organizaciones no gubernamentales, que comprenden la situación desfavorable y de rezago que padecen las minorías étnicas respecto a sus condiciones de vida y de salud. ${ }^{1}$ No obstante este reconocimiento unánime, hay que advertir la escasez y falta de especificidad en la información producida sobre la magnitud de las disparidades en materia de salud entre los pueblos indígenas de América Latina. Son

\footnotetext{
${ }^{1}$ De acuerdo con Margaret Whitehead (2000), el término inequidad tiene una dimensión ética que se refiere, entre otras cosas, a las diferencias en la mortalidad por causas evitables, por lo que deben considerarse injustas e inaceptables. Dichas inequidades pueden fundarse en la desigualdad de oportunidades para el acceso a servicios médicos de calidad y culturalmente competentes; a condiciones de vida inadecuadas, determinadas por factores económicos y sociales restrictivos; a la exposición a riesgos para la salud por condiciones de vida particulares, tales como violencia, estrés o condiciones inadecuadas de trabajo; o a la inaccesibilidad de la atención médica por discriminación étnica o de género.
} 
incipientes los intentos por obtener un diagnóstico preciso sobre el tema y más aún el desarrollo de sistemas de vigilancia epidemiológica étnicamente referenciados. Ello constituye una seria limitante para el diseño y evaluación de intervenciones y políticas de salud tendientes a aminorar la brecha de inequidades entre los indígenas y las sociedades mestizas nacionales.

También es posible testimoniar que, frente a la escasa información sistemática que ha sido generada sobre el tema por el sector salud, contamos con numerosos estudios antropológicos dedicados al estudio de la cultura y las condiciones de vida de los pueblos indígenas autóctonos del continente. No obstante, hay que mencionar que el eje de análisis de los antropólogos ha estado pocas veces orientado hacia la relevancia práctica, clínica o epidemiológica de los aspectos sanitarios, aunque los datos contenidos en estas etnografías son en algunos casos las únicas y escasas evidencias disponibles sobre el tema. Aquí nos interesa explorar datos procedentes de ambas perspectivas - epidemiológica y antropológica — en dos vetas paralelas: sus aportes teóricos y metodológicos para la construcción de un enfoque integrador, como pretende serlo la epidemiología sociocultural, y su aplicación al estudio de un caso concreto: las condiciones de salud de los pueblos indígenas del noroeste mexicano.

Para ello, en el presente trabajo intentamos ofrecer primeramente algunas reflexiones conceptuales sobre el tema de la etnicidad y su relación con la salud desde la óptica de una epidemiología cultural, en el entendido de que el concurso de esta perspectiva nos permitirá integrar resultados de investigación procedentes tanto del campo biomédico y epidemiológico como de la antropología. En un segundo apartado abordamos algunos referentes empíricos producidos en México sobre salud indígena, con especial alusión a esta zona septentrional de México, donde se incluyen datos procedentes del análisis de dos bases de datos — el xil Censo General de Población y Vivienda del INEGi 2001 y la Encuesta Nacional de Salud y Nutrición (ENSANUT) 2006 - realizados por nosotros para un proyecto actualmente en curso (véase nota 1), como también algunas experiencias nuestras de campo. El objetivo primordial del trabajo es realizar un ejercicio de aplicación del enfoque epidemiológico sociocultural para mostrar sus ventajas, las cuales constituirán el motivo del último apartado, a modo de conclusiones.

\section{Etnicidad y salud desde una epidemiología sociocultural}

Abordar la relación entre etnicidad y salud amerita una toma de posición respecto a su conceptualización desde la óptica de una epidemiología socio- 
cultural, en el sentido de que para esta perspectiva resulta relevante no sólo la inclusión de los factores biológicos y ecológicos de la salud, sino además las circunstancias económicas, sociales y políticas, así como los significados culturales que los actores involucrados reconocen en la etiología y la gestión de diversos problemas de salud (Menéndez 1990, 2000). Esto nos sumerge - de entrada - en un tema controversial, por cuanto la definición misma de lo étnico resulta ser problemática en varios aspectos teóricos y metodológicos, en especial por el uso frecuente de esta categoría en términos poco precisos; en algunos contextos es sustituida o equiparada con el concepto de raza (Bhopal y Donaldson 1998). Aunque no son conceptos exactamente sinónimos ni precisamente complementarios, debemos notar que ambos son denominaciones que aluden a la "otredad" con la que los colectivos humanos señalan su diferencia respecto a ciertos grupos poblacionales, a modo de instrumentos conceptuales mediante los cuales construyen su propia identidad, pero que a la vez funcionan socialmente como elementos de discriminación y xenofobia, por lo cual suelen estar cargados de connotaciones ideológicas.

El traslape y la ambigüedad que está patente en ambas categorías alude a la persistencia hasta nuestros días de una tensión existente entre ciencias sociales y ciencias naturales con respecto a un mismo objeto de estudio: el de las diferencias humanas, siendo en lo general "raza" un concepto que intenta basarse en diferencias biológicas y "etnicidad" otro que lo hace con relación a diferencias culturales. ${ }^{2}$ Sin embargo, este acotamiento conceptual no resulta ser nítido y exclusivo, puesto que las diferencias étnico-raciales constituyen un complejo en el que se expresan de forma amalgamada tanto la biología como la cultura. El linaje y las tradiciones son las líneas que mejor resumen el conglomerado genético e histórico que se manifiesta en las diferencias humanas (Macbeth 2001). Cabe señalar que a pesar de los intensos debates sobre la inexactitud del concepto de raza que se dieron a lo largo del siglo xx, aún es frecuente encontrar en biomedicina y epidemiología un uso preferencial de este concepto frente a la categoría de etnicidad. Es algo que puede testimoniarse, por ejemplo, en el uso que tuvieron ambos conceptos en las revistas médicas entre 1985 y 1990, donde resalta el franco predominio de la categoría de raza y la escasa utilización de etnia

\footnotetext{
2 Para Michael Banton (1967), la distinción entre raza y etnicidad es pertinente, dado que estos conceptos aluden a perspectivas distintas: raza es una categorización de los individuos en términos externos (incluso racistas), mientras que etnicidad corresponde a la propia identificación grupal interna. Esta distinción etic/emic quizás sea de utilidad para comprender la preferencia que la biomedicina y la epidemiología tienen por el concepto o categoría de raza, mientras que en ciencias sociales es mucho más común referirse a la etnicidad.
} 
y etnicidad, también lo poco que se estudió el racismo en relación con la salud, hecho que atestigua la abundancia de líneas de explicación preferentemente biológicas (Sheldon y Parker 1992). ${ }^{3}$

¿Por qué la epidemiología y la biomedicina continúan utilizando el concepto de raza a pesar de ser estar reconocida la escasa correlación entre los rasgos morfológicos de las supuestas "razas” (el fenotipo) y las características genéticas (el genotipo) ${ }^{4}$ Aunque es un asunto largamente discutido, debemos advertir que el debate actual gira en torno a si es posible y conveniente clasificar a los seres humanos según una serie de características que ya no se agotan en las apariencias morfológicas externas, pero que expresan, no obstante, ciertas relaciones derivadas del traslape entre genotipos y fenotipos. Para ciertos programas biomédicos y epidemiológicos, como los organizados alrededor del Proyecto del Genoma Humano, tiene utilidad seguir estudiando las diferencias humanas en términos raciales, por cuanto pueden explicar —al menos hipotéticamente- determinados aspectos en materia de salud: desde la vulnerabilidad colectiva a determinadas enfermedades, una respuesta diferenciada a fármacos e incluso ciertos elementos conductuales (Lee, Mountain y Koenig 2001). El planteamiento ha dado origen a una "medicina basada en la raza", cuyos resultados han sido muy controvertidos (Bonham, Warshauer-Baker y Collins 2005). ${ }^{5}$ Porque si bien existen algunas patologías y respuestas fisiológicas de interés clínico que han sido identificadas con respecto a la “condición étnico-racial”, no está aún clara la correlación entre el fenotipo y el genotipo en las diferencias encontradas, ni tampoco en qué medida lo genético puede atribuirse exclusivamente a condiciones heredadas o a mecanismos de adaptación. Por esto, para numerosos autores no se justifica el uso actual de la categoría de "raza". 6 Para otros,

\footnotetext{
3 En comparación, en una revisión sobre lo publicado en dos de las más prestigiadas revistas de antropología médica, el concepto de etnicidad fue utilizado cuatro veces más que el de raza entre 1997 y 2002 (Gravlee y Sweet 2008).

${ }^{4}$ Diversos estudios de la distribución genética actual han encontrado que la mayoría de las variaciones ( 85 por ciento) ocurren entre individuos dentro de cualquiera de las categorías raciales, con una mucho menor proporción ( 5 a 10 por ciento) entre razas, lo cual se ha evidenciado mediante el estudio de proteínas (Lewontin 1972), medidas craneales (Relethford 1994) o niveles de DNA (Barbujani et al. 1997).

5 La opinión actual de la biología evolutiva y de la antropología genética es que las razas que se identifican desde un punto de vista morfológico (fenotípico) no corresponden a linajes genéticos diferenciables, según denotan los análisis de los haplotipos de DNA (Lewontin 1972).

6 La American Association of Physical Anthropology (1996) señaló en una declaratoria que "en la especie humana no existen en la actualidad razas puras en el sentido de poblaciones genéticamente homogéneas ni hay indicios de que hayan existido en el pasado". A la vez, una página editorial aparecida en New England Journal of Medicine (2001) afirmaba que el concepto de raza es en realidad un "constructo social, no una clasificación científica", denunciando la medicina "basada en la raza”, incluida la investigación médica.
} 
en cambio, su utilidad tiene sentido si consideramos los efectos de la discriminación social que operan en condiciones de estigma en relación con el color de la piel y otras características externas. Un ejemplo de ello es la forma en que el racismo y la discriminación pueden afectar los hallazgos epidemiológicos, más que la raza o la etnicidad en sí misma (Bradby 2003; Menéndez 2002; Krieger 2004).

El concepto de etnicidad, de uso preferencial en las ciencias sociales pero actualmente popular también en epidemiología, posee referencias más bien culturales que biológicas. ${ }^{7}$ No obstante, para algunos autores (Coe y Palmer 2005) no está tampoco exento de connotaciones hereditarias, por cuanto expresa la adscripción a un determinado linaje de sangre. Los criterios en su definición son múltiples, señalando —además del linaje — una experiencia histórica colectiva, sentimientos de filiación e identidad, una cultura común y tradiciones diferenciadas, determinado folklore o forma de vestimenta, una lengua propia, a veces una religión distintiva, cierta base territorial; o la existencia de intereses o acciones colectivas que suelen conformar una ideología de alteridad respecto a otros grupos (“otredad”), siendo también conceptualizada la etnicidad como el medio por el cual determinada cultura es transmitida. Por ello, no constituye un sinónimo de cultura, ni de temperamento de un pueblo (ethos, volkgeist) o de nacionalidad, sino que se decanta de los anteriores para señalar su carácter específicamente clasificatorio en términos grupales, que excluye o incluye a los individuos de acuerdo con criterios que pueden estar definidos interna o externamente y que son cambiantes según el contexto donde son planteados.

Siguiendo a Friederich Barth (1976), “ni la comprensión ni la utilización del concepto de 'etnia' destierran el componente biológico de su significado ni su carácter de confrontación social, en tanto que se crea y establece un espacio cultural distinto y enfrentado a otras culturas". Para este autor, el punto clave en la definición de los grupos étnicos no es una cultura propia, la cual puede tener dinámicas distintas a la organización social efectiva, sino

\footnotetext{
7 Para Smith (1997), se documentan al menos tres corrientes de pensamiento sobre el significado de etnicidad. La primera es que corresponde a una cualidad primordial, "que existe de forma natural, desde siempre, que es una de las cualidades dadas de la existencia humana". Una segunda corriente, opuesta a esta visión esencialista, considera que la etnicidad es situacional, ya que "la pertenencia a un grupo étnico es una cuestión de actitudes, percepciones y sentimientos en que se encuentre el sujeto: a medida que va cambiando la situación del individuo, también cambia la identificación del grupo, o, por lo menos, la importancia de las identidades y discursos a las que se adhiere el individuo irá variando conforme pase el tiempo y las situaciones cambien". Un tercer enfoque es el que, según el autor, destaca los atributos históricos y simbólicos y culturales de la identidad étnica. De acuerdo con esta definición, un grupo étnico es "un tipo de colectividad cultural que hace hincapié en el papel de los mitos de linaje y de los recuerdos históricos, y que es conocida por uno o varios rasgos culturales diferenciadores, como la religión, las costumbres, la lengua o las instituciones" (Ibid 18).
} 
la persistencia de límites que permiten la distinción entre miembros y extraños. ${ }^{8}$ Esto implica una concepción no esencialista sino relacional de los grupos étnicos y con ello la existencia de criterios y señales de identificación, pero también de un conjunto de reglas que norman los encuentros sociales interétnicos desde una perspectiva transaccional y procesual, donde la identidad étnica suele sobreponerse a los demás estatus, como la clase social, el género y el rango, debido al carácter imperativo que mantiene en las interacciones sociales.

¿Cómo podríamos conceptualizar las diferencias étnico-raciales desde una perspectiva epidemiológica sociocultural? Desde nuestro punto de vista, que pretende ser sintético e integrador, implica el reconocimiento de tres órdenes diferentes que pueden o no coincidir en su aplicación empírica al estudio de situaciones concretas: el genotipo (la carga genética), el fenotipo (las apariencias "cosméticas” de los individuos) y el ámbito sociocultural de la etnicidad, el cual es dinámico y relacional a la vez que expresa tradiciones y experiencias históricas o intereses compartidos. Todo ello nos lleva a admitir la existencia de elementos diferenciadores que se sitúan en uno o varios de estos tres órdenes distintivos. Respecto al genotipo, significa considerar la distinción genética de linajes que no siempre están ligados a un determinado fenotipo, cuyas pautas pueden tener relevancia epidemiológica. ${ }^{9}$ En cuanto al fenotipo, su importancia radica en que la apariencia física vinculada al concepto de "raza" constituye un marcador de relaciones sociales, aun cuando merezca ser entrecomillado ante las evidencias actuales formuladas por la genética (LaVeist 1996; Krieger 2000; Burchard et al. 2003). Esta posición parte de que no puede dejar de señalarse que tanto la "raza" como el racismo no son realidades obsoletas, puesto que en las sociedades se tes-

${ }^{8}$ A diferencia de la cultura, la cual es de naturaleza dinámica en el tiempo y se compone de rasgos que exhiben los efectos de una ecología cambiante, la identidad étnica supone una estandarización de reglas y roles de interacción que no se limita, aunque se nutra, de los dos órdenes de contenidos culturales que este autor reconoce como centrales del concepto: las señales o signos manifiestos (rasgos diacríticos, como el lenguaje, la vivienda o el vestuario) y orientaciones de valores básicos. De esta manera, las categorías étnicas "ofrecen un recipiente organizacional capaz de recibir proporciones y formas de contenido en los diferentes sistemas socioculturales”. En pocas palabras, si la cultura está definida como un marco interpretativo, un mapa mental o una programación perceptual, lo que define a un grupo étnico es el formato institucional de adscripción a una determinada configuración sociocultural: "es el límite étnico que define al grupo y no el contenido cultural que encierra" (Barth 1976).

9 Las investigaciones actuales identifican la presencia de diversos clusters (conglomerados) poblacionales, indicando que algunas poblaciones tienen mayor mezcla que otras, según pautas migratorias ancestrales (Cavalli-Sforza et al. 1988). Esto ha hecho posible demostrar que la variabilidad genética no exhibe únicamente pautas individuales, sino también grupales, en el sentido de que algunos genes se encuentran más frecuentemente en ciertas poblaciones que en otras, lo cual revela la existencia de conglomerados genéticos definidos por una mayor frecuencia en la presentación de ciertos alelos que predisponen para algunas condiciones patológicas (Hinds et al. 2005). 
timonia hasta la actualidad la distinción de determinadas "razas" o "etnias" como indicadores de diferenciación, como ha ocurrido históricamente con la población indígena y afroamericana en este continente.

La diferencia entre el fenotipo o "raza" y el concepto de etnicidad no tiene una delimitación precisa; por ello hay numerosos autores que prefieren el concepto de "raza/etnicidad”. En ambos casos se alude a linajes, identidades, culturas y, de cualquier manera, a límites de diferenciación. Sin embargo, en lo concerniente al fenotipo, hace referencia a características morfológicas externas, mientras que en la etnicidad no sucede necesariamente así, aun cuando sean asimismo influyentes. ${ }^{10}$ No obstante, ambos conceptos expresan un potencial social discriminatorio, que para la mayoría de los grupos étnicos que son minoritarios —en contextos nacionales o regionales - suele denotar condiciones desfavorables de vida y de salud, con ciertas excepciones respecto a determinadas condiciones patológicas. ${ }^{11}$ Por ello, no cabe duda de que la raza y la etnicidad mantienen relevancia explicativa - e incluso profética - en torno a numerosos problemas de salud, aunque continúen en debate los mecanismos que pueden evidenciar sus relaciones.

Desde nuestra perspectiva, el panorama presentado se refiere a la necesidad de que la investigación de las inequidades en materia de salud aborde el tema de las desigualdades sociales y no sólo el de las diferencias biológicas. El estudio, tanto del genotipo como del fenotipo y sus consecuencias en este campo, señala la distinción de enfoques que están centrados, respectivamente, en el concurso de lo biológico y de las relaciones sociales, mientras que el concepto de etnicidad resulta ser más amplio en su abordaje, puesto que además de expresar la trascendencia de ciertas causales biológicas, no necesariamente genéticas sino también adaptativas al entorno ecológico y a las pautas cambiantes de vida, atañe también al ámbito de las relaciones sociales y al papel que desempeñan los factores culturales en la esfera de la salud. Distinguir estos tres espacios señalados equivale a reconocer la vigencia y validez de programas de investigación que tratan el tema de las diferencias colectivas en cuestiones de salud desde visiones distintivas, aun cuando la composición étnica y fenotípica — que es muy variable según países o regiones - indique la pertinencia disciplinaria de utilizar alguna de estas categorías en forma predominante, de acuerdo con las metodologías empleadas y

10 Kato (1996) refiere, por ejemplo, que un individuo que parece asiático es clasificado como tal, aun cuando no conserve las prácticas culturales de Oriente.

11 Véanse, por ejemplo, las compilaciones de Young (1994), Macbeth y Shetty (2001), LaVeist (2002), Coimbra, Ventura y Escobar (2003) y los trabajos de Sepúlveda (1993) y Jardón (2004). 
también con la disponibilidad de datos en los registros usuales. De esta forma, nos parece válido que desde la biomedicina se investigue la relación del genotipo con la salud y a la vez la relación entre el genotipo y el fenotipo, que es la base endeble del concepto de "raza”, cuya validez a nuestro ver sólo es factible a través de considerarlo un concepto predominantemente social, con el interés de evaluar el impacto de la discriminación racista. En cuanto al concepto de etnicidad, apunta además a incluir la dimensión simbólica en el estudio de los procesos de salud/enfermedad/atención y no sólo el ámbito de lo bioecológico y de las relaciones sociales.

Por esto, para nosotros el concepto o categoría de mayor utilidad y consistencia teórica para estudiar la salud de los pueblos indígenas desde un marco epidemiológico es el de etnicidad, considerando además las altas cuotas de mestizaje y también de cambio cultural que se han manifestado históricamente entre los colectivos étnicos de este país, en condiciones de persistencia de la identidad étnica como las que se testimonian en los pueblos indígenas actuales, en quienes la etnicidad se manifiesta de una forma dinámica y adaptativa, que se expresa de maneras específicas y cambiantes según el contexto propio de cada pueblo, en diversos escenarios situacionales. Así, entendemos que la existencia de límites que marcan la pertenencia a un pueblo indígena se muestra de forma diferenciada en cada grupo étnico, siguiendo criterios propios que asumen a menudo un carácter local. Esto nos plantea la conveniencia de determinar y explicitar diversos criterios que nos permitan determinar metodológicamente la etnicidad, un ejercicio que a nuestro ver debe definirse de acuerdo con el nivel en el cual se plantean las investigaciones. Por ello, el primer paso para un ejercicio diagnóstico sobre la salud de los pueblos indígenas ha de partir del reconocimiento de la especificidad que asumen los criterios de etnicidad en los escenarios locales, lo cual constituye una posibilidad para los acercamientos minuciosos de tipo etnográfico. En el caso de enfoques necesariamente estandarizados, como sucede con las encuestas o los censos, podemos optar por ciertos criterios definitorios, tales como el habla de alguna lengua, la autoadscripción, la residencia en determinado territorio, etcétera. Lo importante es no perder de vista la relevancia de valorar la dimensión étnica como fuente de desigualdades sociales que afectan a la salud de diversos modos, considerar las formas específicas en que los múltiples factores relacionados con la salud se manifiestan en contextos particulares, donde la experiencia histórica frente a la sociedad mestiza, los elementos del entorno ecológico, las pautas de producción, el acceso a mercados laborales, servicios básicos y de salud, el grado de aculturación y otros factores relevantes asumen configuraciones específicas que es preciso evidenciar. 


\section{La condición étnica de los pueblos indígenas de México y del noroeste mexicano}

¿Cómo se establece la etnicidad de los pueblos indígenas de México y, por extensión, del noroeste mexicano? Debemos partir de la situación problemática de que en el país no contamos con datos certeros sobre el tamaño y la localización de los grupos étnicos, ya que tradicionalmente las fuentes de información más sistemáticas han tomado como definitorio sólo el criterio lingüístico, siendo el habla de lengua indígena (HLI) la variable que aparece de forma constante en los censos generales de población desde 1895 (Parra 1950), la cual en el XII Censo del INEGI (2001) se exploró a través de las preguntas “¿habla algún dialecto o lengua indígena?” y “iqué dialecto o lengua indígena habla?”, aplicadas solamente a las personas de cinco años cumplidos o más. El problema estriba en la insuficiencia del criterio lingüístico como elemento definitorio de la condición indígena, iniciando con la ausencia de un consenso acerca de cuáles y cuántas son, el número y tipo de lenguas indígenas y variables dialectales que se hablan en el país. Además, por la subestimación que supone limitarse únicamente al habla de alguna lengua autóctona, debido a la existencia de individuos y también colectivos que son excluidos por este criterio. Como sabemos, hay quienes se consideran a sí mismos y son considerados por otros como indígenas aun cuando no sean hablantes de ninguna lengua indígena, por efectos sinérgicos de la aculturación, la educación, la modernización y la migración. ${ }^{12}$

Por este motivo desde tiempos recientes se está manifestando internacionalmente la tendencia de considerar la identidad como el elemento definitorio de la pertenencia étnica (Matías Alonso 2005), aun cuando la autoadscripción presente asimismo algunas imprecisiones metodológicas, por lo cual algunos autores proponen combinar criterios para obtener una imagen más precisa del tamaño y distribución de los diferentes grupos indígenas que habitan en el país. ${ }^{13}$ En México, la "pertenencia étnica" identitaria se ha

12 Aparecen aquí factores como el avance sistemático del dominio del español como consecuencia de la aculturación educativa y de los medios de comunicación, la negación del habla indígena como resultado del prejuicio discriminador en ámbitos adversos a lo indígena, los casos en los que la lengua se conoce parcialmente o se ha olvidado, la exclusión de los menores de menos de cinco años de edad, a quienes no se aplica la pregunta y la posibilidad de respuestas imprecisas por parte de la única persona a la que se entrevista en cada hogar.

$13 \mathrm{Al}$ considerar la tendencia al subregistro, algunos autores plantean la necesidad de combinar criterios para obtener una imagen más precisa del tamaño y distribución de los diferentes grupos indígenas que habitan en el país. Una primera estrategia en México ha sido la de utilizar el municipio de residencia como proxy de grupo étnico, al caracterizar como indígenas a todos los habitantes de municipios con alta concentración de HLI, procedimiento ciertamente impreciso pero útil para identificar grosso modo per- 
comenzado a explorar en el XII Censo del INEGI a partir de la adscripción que señala la persona que contesta las preguntas por todos los miembros del grupo doméstico censado, con la particularidad de que esta pregunta (“ ¿...es náhuatl, maya, zapoteco, mixteco o de otro grupo indígena?”) fue incluida sólo en el registro muestral del XII Censo ("cuestionario ampliado”), permaneciendo en el marco censal solamente el habla de lengua indígena. ${ }^{14}$

La relativa invisibilidad de lo indígena tiene como consecuencia que no dispongamos siquiera de cifras fidedignas sobre el número de indígenas en este país, constituyendo el rango de las estimaciones de 6 a 20 millones según los criterios utilizados. La cifra más baja se refiere al número total de hablantes de lenguas indígenas (6. 04 millones de HLI) que reportó el XII Censo de 2000, lo cual representaría 6.5 por ciento de la población nacional. Esta proporción sube a 7.7 por ciento si se considera además en forma ponderada a quienes en el cuestionario ampliado respondieron sentirse indígenas y no hablaban una lengua indígena (1.10 millones); este porcentaje se incrementa a 11.8 por ciento al incorporar al total de menores de cero a cuatro años en hogares cuyo jefe de familia es un HLI (1.23 millones), extendiendo la definición al cónyuge o a cualquier ascendiente. Debido a que estas estimaciones pueden aun ser inexactas, el Consejo Nacional de Población (CONAPO) (2001), al analizar la composición de los hogares censados, calculó para ese mismo año la cifra de indígenas en 12403 000, quienes conformarían 13.1 por ciento de la población nacional. No obstante, debemos tomar en cuenta que aun estos cálculos ampliados pueden estar subestimando todavía a la población indígena, pues se documentan cifras

files demográficos, epidemiológicos y de bienestar social. Una segunda propuesta ha sido la de agregar a los HLI montos adicionales que representan a los excluidos por el criterio lingüístico, comenzando por la inclusión — desde el XI Censo General de Población y Vivienda de INEGI (1990), que brinda este tipo de tabulado- de los menores de cinco años pertenecientes a hogares donde el jefe de familia o su cónyuge manifiestan hablar alguna lengua indígena. A la vez, el Instituto Nacional Indigenista estuvo añadiendo sistemáticamente a estas estimaciones el número de personas censadas en sus centros coordinadores que no hablaban alguna lengua indígena, como también el Consejo Nacional de Población (CONAPO) (2001) adoptó una metodología de estimación indígena basada en hogares, a la que se agregan las cifras de indígenas en hogares no indígenas (como sucede con los indígenas que son empleados domésticos) y unas ponderaciones que calculan el número de personas posiblemente excluidas por el criterio lingüístico. Janssen y Martínez (2006) proponen considerar en forma sumatoria tanto el habla de lengua indígena como la identidad (autoadscripción étnica), haciéndola extensiva a todos los individuos que vivan en hogares donde alguno de los miembros mayores de 15 años hable alguna lengua indígena o se defina a sí mismo como indígena, con la exclusión de aquellos hogares donde exista un solo miembro en condición de empleado doméstico.

14 El Instituto Nacional de Estadística, Geografía e Informática (INEGI 2001) efectuó el XII Censo General de Población y Vivienda 2000 con dos tipos de cuestionarios: el básico y el ampliado. El primero fue aplicado a todas las viviendas del país, mientras que el ampliado incluyó una muestra de 2.2 millones de viviendas, a lo que se sumaron algunas preguntas más, como la relativa a la autoadscripción étnica. 
alternas de 12687307 para el mismo año (Janssen y Martínez 2006), resultantes de calificar además como hogares indígenas aquellos donde un mayor de 15 años es HLI. También existen declaratorias políticas realizadas por indígenas que estimaron en 20 millones su número poblacional para 1997 (Asamblea Nacional Indígena Plural por la Autonomía 1997). Considerando la limitante del criterio lingüístico y la falta de especificidad de la autoadscripción (“pertenencia étnica”), estas cifras quizás pudieran estar señalando la magnitud de la subestimación oficial.

Además de la exclusión de numerosos casos que no cumplen con el criterio lingüístico, debemos también acentuar el hecho de que comúnmente en México se tiende a homogeneizar a los colectivos indígenas, como si los factores relevantes para el estudio de la salud o de las condiciones de vida fueran los mismos en las rancherías de la Alta Tarahumara, en la Selva Lacandona o en el altiplano poblano, pasando por alto precisamente aquello que se busca evidenciar: la forma en que lo sociocultural que es concomitante con lo étnico se expresa diferencialmente en las distintas situaciones en que hoy se encuentran los individuos y pueblos de origen y cultura indígena. En México existen grupos etnolingüísticos con gran número de población (nahuas, mayas, mixtecos, zapotecos, otomíes, tzeltales y tzotziles, quienes cuentan entre sus miembros entre 300000 y 1400000 individuos, en contraste con grupos muy pequeños, como los kiliwas, paipai, cochimíes, kukapás, kikapúes, con menos de 500 miembros por grupo. En todo caso, es muy amplia la diversidad cultural y lingüística en el país, donde se hablan — según diversos cálculos — entre 60 y 90 lenguas y cerca o más de 300 dialectos. ${ }^{15}$ Es de suponer, además, que las diferencias no son solamente culturales sino también socioeconómicas y ecológicas, puesto que los indígenas mexicanos viven en la actualidad en muy diferentes situaciones respecto a su organización social, pautas migratorias y grados de incorporación a la cultura nacional. Para nuestro objetivo, la revisión de algunos hallazgos relativos a la situación de salud de los pueblos indígenas del noroeste mexicano y su contraste con datos sobre los indígenas a escala nacional nos servirá para mostrar la necesidad de particularizar nuestra mirada diagnóstica.

En el caso del noroeste mexicano, tampoco contamos con cifras precisas para estimar la población indígena, si bien, desde nuestra perspectiva, hay varios elementos relevantes para proponer la validez de estudiar a los pue-

15 El rango varía de 57 lenguas indígenas (Jardón 2004), 64 lenguas y 364 variedades lingüísticas (Instituto Nacional de Lenguas Indígenas 2005), 81 (De la Vega 2001), 91 (Instituto Nacional de Estadística, Geografía e Informática 2001) o incluso 289, según el Summer Institute of Linguistics (Gordon 2005). 
blos indígenas de esta zona del país en forma diferenciada a los del resto de México. Uno de ellos es la idea de que el noroeste de esta nación puede ser conceptuado como una unidad particular de análisis, debido a factores de contigüidad geográfica, pero también con base en elementos históricos, ecológicos, económicos y socioculturales, que son compartidos en mayor o menor grado por estos colectivos étnicamente diferenciados. ${ }^{16}$ ¿Quiénes son los indígenas en el noroeste? Responder esta pregunta no es ciertamente fácil, por cuanto, desde nuestra perspectiva, consideramos que la respuesta amerita distinguir a la población considerada "autóctona" que vive dentro y fuera de sus territorios tradicionales, pero asimismo incluir a los numerosos indígenas inmigrantes del centro y sur de la república que aquí habitan, quienes constituyen hoy un colectivo sin duda muy numeroso, pues la migración ha cambiado de manera significativa la composición étnica de todas las entidades federativas del noroeste mexicano. Además, al igual que en el contexto nacional, las diferencias por lo que se refiere al uso de criterios es relevante. Como podemos ver en el cuadro 1, basado en cálculos realizados por CDI-PNUD (2006) con los datos del XII Censo General de Población y Vivienda del 2000, la población indígena en el noroeste es de 622525 individuos, constituyendo 2.9 por ciento de la población total (poco más de 21.7 millones) en el conjunto de los nueve estados que aquí incluimos. De acuerdo con estos cálculos, Nayarit es la entidad con mayor proporción indígena respecto a la mestiza (6.1 por ciento), seguida por Sonora (5.7) y Chihuahua (4.5). No obstante, hay que destacar que es el estado de Chihuahua el que cuenta con el mayor número de indígenas en este conjunto (136 589 individuos), con Sonora en segundo término (126

\footnotetext{
16 El noroeste constituye una amplia zona geográfica que puede ser delineada como una superárea cultural que contiene elementos comunes y a la vez heterogéneos. La variedad ecológica y cultural es una de las características centrales de esta zona geográfica, la cual, para fines de este trabajo, abarca los estados mexicanos de Sonora, Sinaloa, Chihuahua, Baja California, Baja California Sur, Durango, Coahuila, Nayarit y Jalisco. ¿Cómo definir el noroeste? Debemos partir de que existen varias propuestas diferentes de regionalización que abarcan a algunos de los estados mexicanos que estamos considerando. Asimismo, estas y otras entidades hoy estadounidenses han sido también incluidas para integrar otras propuestas regionales, lo cual es, por tanto, el tema de gran debate tanto en nuestro país como en el vecino. Véase Moore (1954), Bassols (1972), Parry (1972), León Portilla (1972), Spicer (1962), Hedrick, Kelley y Riley (1974), Beals (1974), Byrkit (1992) y Riley (1994). En México, las propuestas quizás más influyentes son aquellas que imaginan a todo el norte mexicano como una región muy distinta del centro y sur del país, basadas por lo general en elementos fisiográficos y económicos, pero que incorporan raramente criterios relativos a la etnicidad, algo que sí sucede con estudios históricos, antropológicos y arqueológicos, los cuales supondremos más idóneos para nuestro objetivo al tener como fundamento, precisamente, los rasgos culturales de los pueblos indígenas, generalmente bajo el concepto de área cultural. En varios de estos estudios encontramos planteamientos que defienden la idea de que el norte de México constituye un zona cultural que es definida en términos vagos, "como el área geográfica situada fuera de las fronteras mesoamericanas" y que representa todavía, por la escasez de estudios, "un enigma para la antropología mexicana" (Sariego 2002).
} 
535), Sinaloa en el tercero (87 948), Jalisco en el cuarto (75 122) y Nayarit en el quinto lugar (56 172), seguido por Durango (39 545). Como puede apreciarse en el cuadro 1, los estados con menor presencia indígena son Baja California Sur y Coahuila. Cabe señalar la posible subestimación en estos cálculos de la población indígena en el noroeste mexicano, pues según la metodología ampliada propuesta por Janssen y Martínez (2006) es necesario incorporar en la cuantificación no solamente a los HLI y a quienes viven en hogares donde el jefe de familia o el cónyuge son hablantes de lengua indígena, sino además a quienes declaran percibirse a sí mismos como indígenas o habitan en viviendas donde el jefe de familia o su cónyuge declaran sentirse indígenas. Siguiendo esta metodología, en el análisis que realizamos de los resultados del cuestionario ampliado del XII Censo la proporción ponderada de indígenas para el noroeste se amplía a 3.7 por ciento, según puede verse en el cuadro $2 .{ }^{17}$

\section{Cuadro 1}

Población indígena en entidades federativas del noroeste mexicano 2000

\begin{tabular}{|l|l|r|r|r|r|}
\hline Clave & Entidad federativa & Total & $\begin{array}{r}\text { Población } \\
\text { indígena }\end{array}$ & $\begin{array}{r}\text { Población } \\
\text { no indígena }\end{array}$ & $\begin{array}{r}\text { \% de población } \\
\text { indígena }\end{array}$ \\
\hline & República mexicana & 97483412 & 10253627 & 87229785 & 10.5 \\
\hline 02 & Baja California & 2487367 & 81679 & 2405688 & 3.3 \\
03 & Baja California Sur & 424041 & 11481 & 412560 & 2.7 \\
05 & Coahuila & 2298070 & 7454 & 2290616 & 0.3 \\
08 & Chihuahua & 3052907 & 136589 & 2916318 & 4.5 \\
10 & Durango & 1448661 & 39545 & 1409116 & 2.7 \\
14 & Jalisco & 622002 & 75122 & 6246880 & 1.2 \\
18 & Nayarit & 2536844 & 87948 & 2448896 & 3.1 \\
25 & Sinaloa & 2216969 & 126535 & 2090434 & 5.7 \\
26 & Sonora & 21707046 & 622525 & 21084521 & 2.9 \\
\hline
\end{tabular}

Fuente: elaboración propia con datos de CDI-PNUD (2006). Los cálculos de población indígena incluyen hablantes de lengua indígena, autoadscripción étnica y a quienes viven en hogares donde el jefe o cónyuge habla lengua indígena.

17 El Instituto Nacional de Estadística, Geografía e Informática (INEGI) efectuó el XII Censo General de Población y Vivienda 2000 con dos tipos de cuestionarios: el básico y el ampliado. El primero fue aplicado a todas las viviendas del país, mientras que el ampliado incluyó una muestra de 2.2 millones de viviendas, donde se agregaron algunas preguntas más, como la relativa a la autoadscripción étnica. Para nuestro análisis elaboramos una nueva variable (etnicidad ampliada al hogar) en dos etapas: primero, considerar como indígenas a todas aquellas personas que dijeron hablar una lengua indígena o manifestaron sentirse indígenas; segundo, incluir a todos los habitantes de los hogares donde el jefe de familia o cónyuge eran indígenas. 


\section{Cuadro 2}

Noroeste de México: Estimación de la población indígena según diferentes criterios de etnicidad 2000

\begin{tabular}{|c|c|c|c|c|c|c|c|c|}
\hline \multirow{2}{*}{$\begin{array}{l}\text { Respuestas } \\
\text { Respuestas }\end{array}$} & \multicolumn{2}{|c|}{$\begin{array}{c}\text { Habla alguna } \\
\text { lengua indígena } \\
(\mathrm{HLI})\end{array}$} & \multicolumn{2}{|c|}{$\begin{array}{l}\text { Pertenencia étnica } \\
\text { (PE, se siente } \\
\text { indígena) }\end{array}$} & \multicolumn{2}{|c|}{$\begin{array}{c}\text { Es hablante de lengua } \\
\text { indígena o se } \\
\text { autoadscribe indígena } \\
\text { (HLI O PE) }\end{array}$} & \multicolumn{2}{|c|}{$\begin{array}{c}\text { Etnicidad ampliada } \\
\text { al hogar } \\
\text { (HLI+PE+miembros } \\
\text { de sus hogares) }\end{array}$} \\
\hline & $\mathrm{N}$ & $\%$ & $\mathrm{~N}$ & $\%$ & $\mathrm{~N}$ & $\%$ & $\mathrm{~N}$ & $\%$ \\
\hline Sí & 359325 & 1.9 & 365309 & 1.9 & 519633 & 2.7 & 805886 & 3.7 \\
\hline No & 18723327 & 97.7 & 18172134 & 94.8 & 18563477 & 96.9 & 20725913 & 96.1 \\
\hline No especificado & 76184 & 0.4 & 621393 & 3.2 & 75726 & 0.4 & 37266 & 0.2 \\
\hline Total* & 19158836 & 100 & 19158836 & 100 & 19158836 & 100 & 21569065 & 10 \\
\hline
\end{tabular}

Fuente: elaboración propia con datos contenidos en el XII Censo General de Población y Vivienda, 2000. Muestra censal, registros ponderados. Se excluyeron los registros sin respuesta.

¿Qué aportes pudiera hacer una epidemiología sociocultural en la consideración de estos datos? En primer término, cabe señalar que tanto el criterio lingüístico como el de autoadscripción pueden resultar imprecisos, por cuanto representan criterios formulados externamente a los grupos étnicos, quienes poseen límites distintivos con respecto a la pertenencia grupal. A la vez, interesa hacer notar el fenómeno de la etnogénesis, el cual apunta a varios aspectos relativos a la etnicidad. Por ejemplo, el carácter inclusivo o no de una persona en un grupo étnico de acuerdo con las alianzas matrimoniales, o con el reconocimiento de los hijos de un matrimonio mestizo. Asimismo, porque, como parte de la etnogénesis, se encuentra el fenómeno de numerosos individuos que, ante determinadas circunstancias, deciden asumirse como indígenas, incluso en casos en los que no existe la adscripción a un linaje de sangre. Lo anterior nos advierte de la dificultad inherente al ejercicio de situar claramente la etnicidad, aludiendo tanto al carácter difuso que posee en algunos casos como a la existencia de numerosos casos híbridos y de criterios locales para determinar las identidades étnicas (Garduño 2001).

Desde nuestra experiencia con uno de los grupos del noroeste, el de los mahkurawe o guarijíos de Sonora, por ejemplo, en una investigación realizada entre 1992 y 1996, nuestro interés se centró desde el inicio en efectuar una comparación entre la población indígena y la "yori" o blanca, encontrando de entrada que los datos contenidos en los expedientes clínicos de la Unidad Médica Rural del Programa IMSS-COPLAMAR raramente consignaban la catego- 
ría étnica de los pacientes tratados. Con la ayuda de informantes locales, pudimos percatarnos de que existía un sistema local muy preciso de adscripción étnica, en el que todos compartían la misma visión sobre quiénes eran los indígenas y quiénes los “yoris”, basado fuertemente en el parentesco; mientras que en un segundo momento pudimos enterarnos de numerosos casos limítrofes, que abarcaban individuos concretos como producto del mestizaje entre "yoris" (siempre del sexo masculino) con mujeres indígenas, pero también a individuos de origen más o menos blanco que se habían emparentado con mujeres indígenas y se habían integrado al grupo étnico mahkurawe-guarijío, a veces por razones de conveniencia económica, como el hecho de gozar de las ayudas gubernamentales o ser sujetos de derechos ejidales. También, de comunidades enteras (el caso de Guajaray), cuyos integrantes eran más bien mestizos de origen mayo, pero que con el pasar de los años comenzaron a integrarse al grupo guarijío por las mismas razones de conveniencia, incorporando incluso la enseñanza de la lengua

\section{Cuadro 3}

Grupos indígenas “autóctonos” en el noroeste mexicano

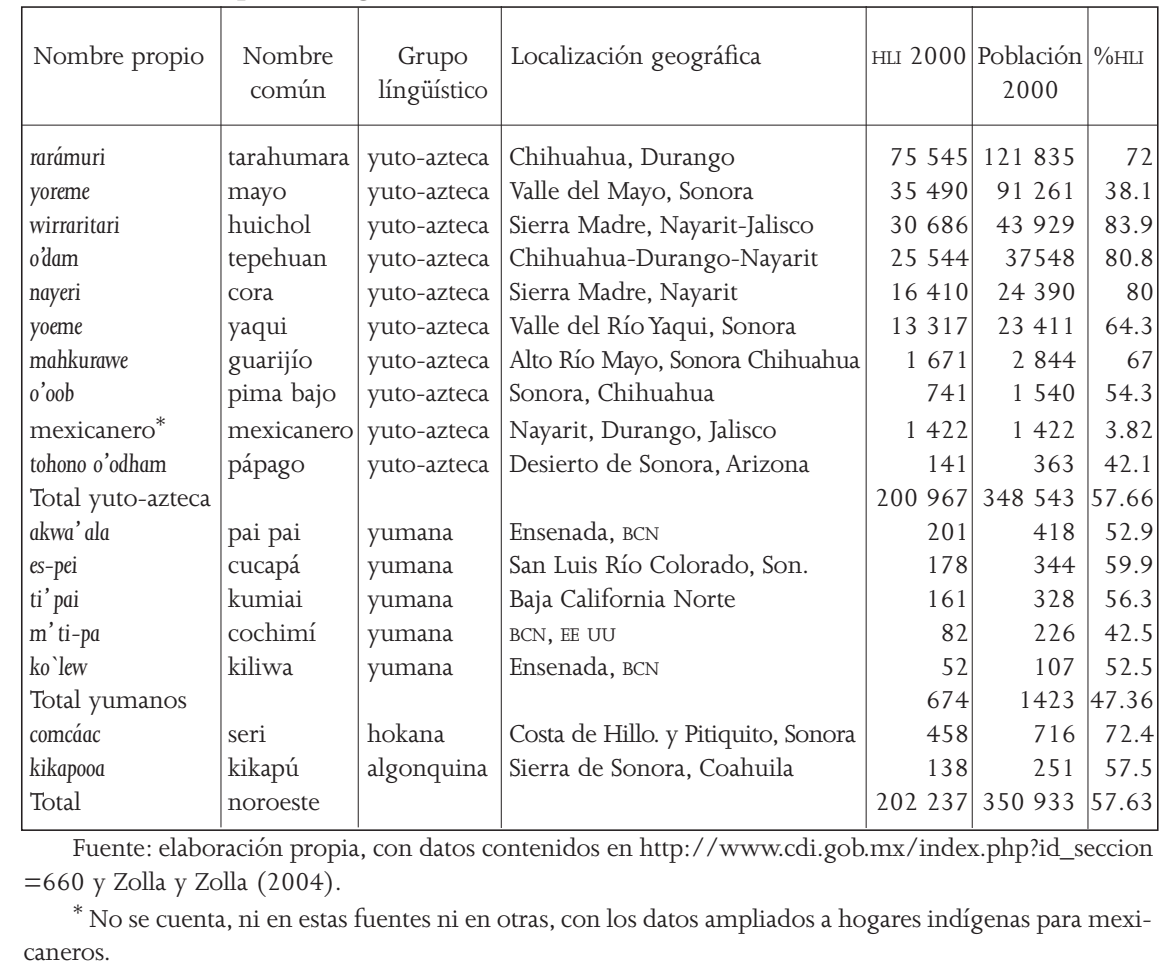


mahkurawe para los escolares y el aprendizaje de rituales propiamente mahkurawe-guarijío (como el tuburi, que no se encuentra entre los indígenas mayos). Esto nos llevó a introducir en nuestra indagación una tercera categoría: la de los "mezclados", que ofreció hallazgos de condiciones de vida y de salud para ciertas condiciones más desfavorables que para los meramente mahkurawes o la población yori de la región (Haro et al 1998).

Respecto a la composición étnica, destaca que la mayoría indígena en el noroeste esté formada por inmigrantes del centro y del sur del país, calculando nosotros que constituyen 67.5 por ciento de los indígenas en el conjunto de los nueve estados del noroeste: 420288 individuos que nos resultan de restar del total calculado por CDI-PNUD (2006) a los integrantes de las etnias que actualmente se consideran autóctonas del noroeste: 202237 individuos, que constituyen según nuestro cálculo una proporción de 32.5 por ciento del total indígena del noroeste. El cuadro 3 ilustra algunos datos pertinentes sobre los pueblos considerados autóctonos en esta región del país.

\section{Salud indígena y condiciones de vida en México y en el noroeste mexicano}

A pesar de las limitantes señaladas con respecto al estado del conocimiento, resulta obvio que los estudios realizados sobre el tema coinciden en destacar el importante rezago que presenta en lo general la población indígena del país con relación al resto de la sociedad mexicana, lo cual se expresa principalmente en los rubros de mortalidad, morbilidad, nutrición y acceso a servicios de salud. No obstante, interesa señalar que el grado de agregación de los datos, las metodologías empleadas y en particular los criterios de etnicidad que han sido empleados mantienen en un alto grado de imprecisión respecto a la calidad y alcance diagnóstico de estos datos, por cuanto no distinguen la situación epidemiológica en que se encuentran los pueblos indígenas respecto a su lugar de residencia (según tamaño de localidad), como tampoco denotan la especificidad étnica que asumen los aspectos de salud, siendo estos aspectos que en nuestras investigaciones sobre los pueblos indígenas del noroeste mexicano conservan particular relevancia.

¿Qué indicadores podemos considerar para evaluar el estado de salud de los pueblos indígenas? Debemos señalar la arbitrariedad inherente a este ejercicio, por cuanto tenemos que partir de que la salud tiene componentes tanto objetivos como subjetivos, biológicos, sociales y también psicológicos y culturales, lo cual nos induce al menos a considerar y reflexionar sobre la forma en que las culturas indígenas conceptualizan a su modo lo que es una 
vida saludable y también qué aspectos pueden calificarse como daños o riesgos para la salud. Sin embargo, es preciso establecer que un ejercicio de estas características apenas resulta posible en estudios etnográficos, pero no en un ejercicio como el presente, en el cual intentamos obtener un panorama general dirigido a la comparación sobre la salud de la población indígena con el resto de la población nacional. Para ello, nos limitaremos a ofrecer un repaso basados en algunos indicadores que nos parecen elocuentes para ilustrar el estado de las inequidades sociales y su impacto en materia de salud, desde una perspectiva epidemiológica sociocultural que intentará analizar la situación de la salud en los pueblos indígenas con base en indicadores socioeconómicos, demográficos y también epidemiológicos, incluyendo algunos sobre atención a la salud.

La esperanza de vida en 1995 se calculó, según fuentes oficiales, en casi cinco años menos para los indígenas mexicanos (69.5 años) que para el promedio nacional de 73.7, mientras que para 2000 (Secretaría de Salud 2001a) esta diferencia fue calculada siete años inferior al resto de la población (69/76). Un estudio más específico de Funsalud señala que para 19901996 en los municipios indígenas la esperanza fluctuó de 62 a 65 años, cuando la nacional era de 70 años (Torres et al. 2003). Interesa mencionar que estos cálculos se basaron exclusivamente en datos obtenidos en el ámbito municipal en aquellos identificados como municipios indígenas, por lo que su especificidad puede considerarse escasa. Con respecto al noroeste, cabe mencionar que no se cuenta con estimaciones siquiera aproximativas en el caso de los pueblos indígenas, pero sí indicios de que la EV se encuentra por debajo del promedio de los estados debido a ciertos indicadores relativos a la incidencia de muertes en edades más tempranas.

Aun ante la escasez de estudios específicos sobre el tema de acuerdo con ciertos indicadores, la salud de los pueblos indígenas en el noroeste mexicano se ha modificado sustancialmente en particular a lo largo del siglo xx, siendo hoy muy diferente el panorama al encontrado a inicios del mismo siglo, cuando el americanista Ales Hrdlicka (1908) realizó varias visitas a esta zona del país reportando la buena salud de los nativos del Gran Noroeste mexicano, refiriendo que su saludable estilo de vida los hacía inmunes al cáncer y que poseían algún tipo de protección natural contra las enfermedades. Digno es de señalarse, no obstante, que su diagnóstico fue poco acucioso y dirigido a recios sobrevivientes, puesto que debido al contacto con los españoles en el siglo xvi, los pobladores autóctonos del noroeste mexicano experimentaron una severa merma en su número por causa de epidemias, exterminio e integración, registrándose una recuperación demográfica (en los grupos que lograron sobrevivir) lenta pero consistente desde fines del siglo XIX y comenzando a mostrar signos de transición epidemiológica (dis- 
minución de mortalidad general e infantil y decremento en la fecundidad) hasta mediados del siglo xx.

Debido a que en México no se considera la variable etnicidad en los certificados de nacimiento y defunción, ni tampoco en los registros de egresos hospitalarios o de consulta ambulatoria, resulta imposible contar con un panorama epidemiológico que permita reconstruir sistemáticamente el perfil de salud de los pueblos indígenas del noroeste o del resto del país. No obstante, contamos con algunas evidencias que nos permiten suponer que se expresan diferencias importantes entre los mismos grupos étnicos de esta región y del país. En el vecino estado de Arizona, por ejemplo, según datos del Indian Health Service (IHS) para el año de 2001 (Mrela y Coe, 2002), los nativos americanos mueren en promedio a edad más temprana (54.3 años) que los afroamericanos (59.1), los hispanos (58.4), los asiáticos (63.9) y la población blanca anglosajona (74.2), señalando con esto la persistencia de un franco diferencial ante el riesgo de morir, cuyas principales causas son las enfermedades del corazón y el cáncer, seguidas de accidentes, diabetes, males relacionados con el alcohol, afecciones hepáticas y renales, respiratorias agudas y suicidios, entidades en que los nativos muestran mayores tasas que el promedio. En el lado sonorense, un estudio nuestro en El Colegio de Sonora (Haro et al., 1998) mostró en el caso del pueblo mahkurawe (guarijío) una tasa de mortalidad general tres veces mayor que el promedio sonorense en 1990, siendo las principales causas las muertes violentas, las de tipo obstétrico y perinatal, infecciones intestinales, otras infecciones, accidentes y enfermedades respiratorias agudas. Encontramos este perfil relacionado con la pobreza, las malas condiciones higiénicas y de saneamiento y un pobre acceso a los servicios de salud. Si bien las condiciones históricas, políticas y de salud son distintas para los pueblos indígenas a ambos lados de la frontera, merece destacarse que sus perfiles epidemiológicos denotan en ambos países situaciones de marginación social y una mayor vulnerabilidad frente a procesos sociales asociados a la modernidad y la aculturación de estos colectivos (Haro 2004). Es una situación que se manifiesta igualmente a escala nacional, aun cuando los datos usuales no distinguen condiciones específicas para los diferentes grupos étnicos. ${ }^{18}$

\footnotetext{
18 A pesar de que en los certificados de defunción no se consigna la adscripción étnica, existen evidencias de que el nivel de mortalidad entre la población indígena de México es al menos 30 por ciento superior al de los no indígenas, calculándose (Consejo Nacional de Población 1998) aún mayor entre las mujeres (36 por ciento) que entre los hombres (25). Entre las causas de la mortalidad general indígena destacan las enfermedades infecciosas, que en 1998-1999 manifestaron un peso relativo de casi el doble ( 16 por ciento de la mortalidad general atribuida a indígenas) que en el nivel nacional (9 por ciento), cuando entre la población general las cinco primeras causas de muerte correspondieron a enfermedades no transmisibles. Entre los indígenas las infecciones intestinales ocuparon como promedio en este bienio
} 


\section{Cuadro 4}

Mortalidad infantil por grupo étnico en México 1990-1995 (Defunciones por mil nacidos vivos en municipios indígenas considerados por entidades federativas)

\begin{tabular}{|c|c|c|c|}
\hline Grupo lingüístico & Entidades & 1990 & 1995 \\
\hline Huichol & Jalisco & 100.01 & \\
\hline Tarahumara & Chihuahua & 95.28 & \\
\hline Cora & Nayarit & 82.3 & \\
\hline Chocho & Oaxaca & 79.1 & \\
\hline Cuicateco & Oaxaca & 77.85 & \\
\hline Totonaca & Puebla-Veracruz & $68.9^{*}-57.07$ & 57 \\
\hline Mixteco & Guerrero-Oaxaca-Puebla & $70.7^{*}-66.85$ & 56.2 \\
\hline Mazateco & Oaxaca & 65.22 & 44.7 \\
\hline Huasteco & Veracruz & $61.6^{*}-55.18$ & 53.6 \\
\hline Tzeltal & Chiapas & $68.1^{*}-53.31$ & 53.4 \\
\hline Tzoltzil & Chiapas & $66.7^{*}-64.9$ & 52.6 \\
\hline Tepehuán & Durango & 64.2 & \\
\hline Náhuatl & Oaxaca-Puebla-Veracruz & $64.1-60.5^{*}$ & 48.3 \\
\hline Chol & Chiapas & $62.9^{*}$ & 47.2 \\
\hline Mazahua & México & $70.8^{*}$ & 44.7 \\
\hline Zapoteco & Oaxaca & $51.3^{*}-34.1$ & 40.4 \\
\hline Otomí & México & $69.52-51.9^{*}$ & 40.1 \\
\hline Maya & $\begin{array}{l}\text { Yucatán-Quintana Roo } \\
\text {-Campeche }\end{array}$ & $48.2^{*}-35.0$ & 37.9 \\
\hline
\end{tabular}

Fuente: elaboración propia con base en Consejo Nacional de Población 1998 y Fernández Ham 1993. Las cifras con asterisco son las de CONAPO.

Esto se muestra en rubros como la mortalidad y la sobrevivencia infantil, aludiendo ambos a áreas críticas en materia de salud indígena. En cuanto a la mortalidad infantil, destaca que, según ciertos datos disponibles, presenta tasas más altas en el caso de algunas de las etnias del noroeste con respecto al promedio nacional e incluso en relación con otros grupos étnicos del centro y sur de la república. Aunque la mortalidad indígena infantil pare-

el primer lugar como causa de muerte, siendo la tasa de mortalidad por diarrea de 34 muertes indígenas por cada 100 mil habitantes, contra 11 a escala nacional. Otra enfermedad transmisible que presentó tasas tres veces mayores fue la tuberculosis pulmonar (nueve muertes por 100 mil indígenas contra cuatro a escala nacional), constituyendo en el periodo analizado la tercera causa de mortalidad general en el medio indígena y la cuarta las enfermedades respiratorias agudas (neumonía e influenza), con tasas comparativas de 29 en indígenas contra 22 a escala nacional. Se encontraron asimismo fuertes contrastes en la mortalidad por causas obstétricas, siendo las muertes maternas la segunda causa de muerte entre indígenas con tasas tres veces más altas que a escala nacional (14 contra 4, respectivamente). INEGI-SSA. Cinta de Mortalidad Promedio 1998-1999, citada en Secretaría de Salud 2001 a. 
ce haber descendido a escala nacional de una tasa de 60.9 por mil nacidos vivos en 1990 a 48.3 en 1995 y 38.5 en 2000 (cuando la tasa respectiva fue de 24.9 para los no indígenas), hay que subrayar que es 58 por ciento mayor al promedio nacional (Secretaría de Salud 2001a; Machinea, Bárcena y León 2005). Los datos no muestran consistencia debido a la diferencia de criterios en los municipios considerados para su cálculo, señalando algunos trabajos tasas más altas para grupos indígenas asentados en "municipios predominantemente indígenas” (definidos aquí como aquellos con más de un 40 por ciento de HLI) en los estados de Chihuahua, Jalisco y Nayarit, con diferencias interétnicas relevantes, que pueden apreciarse en el cuadro 4. Otro indicador crítico es el de sobrevivencia infantil calculado por CDI-PNUD (2006). ${ }^{19}$ En el conjunto de todas las entidades federativas es significativamente menor en indígenas (0.7380) cuando se compara con no indígenas (0.8491), siendo la brecha de 13.1 por ciento a escala nacional (datos del 2000 en CDI-PNUD 2006). Sin embargo, las mayores brechas interétnicas se observaron en estados del noroeste de la república: Chihuahua (30.5 por ciento), Nayarit (28.8), Durango (21.8) y Sinaloa (20.1 por ciento). Estos datos, no obstante su elocuencia, adolecen del ejercicio de diferenciar dentro de las regiones estudiadas (en este caso municipios) la mortalidad que se expresa en indígenas y no indígenas. Es un tema pendiente en el diagnóstico de la salud indígena.

En nuestra experiencia de trabajo en la región mahkurawe-guarijío la tasa de mortalidad infantil estimada en el periodo 1976-1995 fue de 41.7, mientras que para 1988 la tasa respectiva para Sonora fue de 21.7. Interesa señalar que entre las causas de muerte de todos los menores de cinco años destacaron las asociadas al periodo perinatal, las enfermedades diarreicas y otras enfermedades infecciosas, de origen desconocido, respiratorias agudas y accidentes. Estas causas son mucho mayores entre niños guarijíos, seguidos de infantes mestizos que entre los hijos de la población "yori” o blanca (Haro et al. 1998). A la vez es importante recalcar que las causas de

\footnotetext{
19 El informe de CDI-PNUD (2006) señala que "la sobrevivencia infantil es considerada el indicador más sensible del estado de salud de una población”, pues refleja la existencia de servicios médicos y sanitarios y un acceso equitativo a ellos, además de estar asociado a la nutrición de la población. Esta fuente estima que el índice de sobrevivencia infantil (ISI) es una alternativa para evaluar la salud en situaciones de escasa población, como las municipales, donde se dificulta calcular la esperanza de vida, considerándose que el IsI es un proxy de este indicador. Su generación incluye tomar en cuenta la tasa de mortalidad infantil, el número de defunciones de niños menores de un año y el número de nacidos vivos en el municipio. Su ponderación para construir el índice de desarrollo humano (IDH), que además de educación e ingreso, comprende un complejo cálculo que considera el índice de esperanza de vida a nivel nacional, el valor máximo conocido de ISI (Japón, con 0.997), la tasa de mortalidad infantil nacional, el número de municipios en el país y el porcentaje de la población nacional que habita en el municipio donde se calculará el IDH (Programa de las Naciones Unidas para el Desarrollo-México 2007).
} 
mortalidad vinculadas a la falta de atención obstétrica y perinatal constituyeron 12.3 por ciento de la mortalidad general, siendo responsable de la muerte de seis mujeres y ocho recién nacidos en el periodo. ${ }^{20}$

¿Cómo podemos analizar estos indicios desde una perspectiva epidemiológica sociocultural? Para comenzar, debemos estar atentos a la relevancia que mantiene el subregistro de los hechos vitales en las regiones indígenas, atendiendo a la necesidad de realizar estudios realmente específicos, en combinación de técnicas estadísticas e indagaciones de base etnográfica. Por otra parte, corresponde advertir ciertos indicios que surgen tanto en el trabajo de campo como en estudios cualitativos efectuados por distintos autores en épocas diversas, lo que nos permite observar los cambios epidemiológicos subyacentes. Por ejemplo, en mi primera experiencia de trabajo entre los guarijíos (Haro 1981) me tocó presenciar la muerte de una niña a causa de una intoxicación con Datura inoxia (toloache). En aquel entonces, como médico pasante en servicio social, suponía que sería un grave trauma para sus padres, manifestando mi sorpresa cuando al día siguiente escuché al padre de la criatura decir en la red telefónica rural que "ya habían estado encargando el otro”. Pasaron muchos años antes de entender, gracias a lecturas antropológicas posteriores (Scheper-Hughes 1997), que esta actitud ligera hacia la mortalidad infantil es típica de situaciones en donde el fenómeno se presenta con elevada frecuencia. Pasar de una perspectiva relativista, como la de cierto culturalismo antropológico, a una dimensión basada en el daño evitable, donde las representaciones sociales — en este caso de la

20 No tenemos tampoco datos certeros para evaluar la magnitud de la mortalidad materna en las regiones indígenas del noroeste; pero hay evidencias de las diferencias existentes. Las estimaciones realizadas a escala nacional suelen señalar que es tres veces más frecuente que entre las no indígenas. Un estudio llevado a cabo en estados con alta proporción indígena (Espinosa 2003) mostró que el riesgo de muerte materna es en cuatro de estos estados (Oaxaca, Chiapas, Guerrero e Hidalgo), 2.96 veces mayor que en el resto del país, calculando que para 1999, año del estudio, la tasa más alta de mortalidad la obtuvieron las zonas indígenas de Guerrero (283 muertes por 100 mil nacidos vivos, en contraste con 51 en el promedio nacional y 70 en el estatal); seguido por Oaxaca (120 en zonas indígenas y una tasa de 58 a nivel estatal) y por Chiapas (110/70, respectivamente) e Hidalgo (91/50). Una investigación fundamentalmente etnográfica realizada en la localidad indígena tzotzil de Chenalhó, en Chiapas (Freyermuth 2003), señala con todo detalle el grave problema que representa la mortalidad materna en zonas indígenas, mencionando cómo en Chenalhó pasó de 7 (en 1998-1991) a 32 (en 1994-1995), cuadriplicando su incidencia, manifestando además un subregistro de 44 por ciento de las muertes maternas, que fue, no obstante, menor en relación con otras causas (68.4 por ciento). Revela también la importancia de la muerte materna como segunda causa de fallecimiento entre las mujeres en Chenalhó, sobre todo entre las de 15 a 29 años, siendo las principales las ocurridas durante el parto, seguidas de las hemorragias en la gestación. Otro estudio realizado en 1990-1 mediante encuesta a 349 familias huicholas del estado de Jalisco encontró un total de 5 muertes maternas y 208 el número de nacidos vivos en el mismo periodo, estimando una razón de mortalidad materna de 2,403.6 por 100mil, significativamente más alta que la correspondiente a Jalisco (24 por 100mil). Los cinco casos de muertes maternas correspondieron a causas maternas directas (infección puerperal y hemorragia) durante el puerperio; ninguna de las mujeres recibió asistencia médica (Blanco et al. 1994). 
mortalidad infantil - pueden (y deben) ser vistas como marcadores de daños evitables. Éste es un rasgo que según nosotros debe caracterizar a una epidemiología sociocultural (Hersch y Haro 2007). La referencia a estos fenómenos nos lleva a buscar activamente los casos no registrados, según pudimos comprobar posteriormente al realizar un inventario comunitario de la mortalidad en la región (Haro et al 1998), que nos permitió percatarnos de la importancia del subregistro de estas y otras muertes debido a la lejanía del Registro Civil en la zona mahkurawe.

Desde este enfoque, la mirada diagnóstica implica a la vez relacionar datos relevantes que pueden resultar inconexos a primera vista. En el caso del noroeste mexicano, nos interesa destacar la cuestión de la relativa invisibilidad que tiene el mundo indígena, un factor que tiende a soslayar la importancia de la etnicidad en una sociedad que se considera a sí misma hegemónicamente mestiza, en contraste con entidades federativas donde lo indígena está amalgamado con el glorioso pasado mesoamericano y maya (Oaxaca, Chiapas, Puebla, Hidalgo, Yucatán) y hacia donde se canalizan la mayor parte de los recursos destinados a mejorar las condiciones de vida indígenas, sin considerar los grandes rezagos que aún persisten en el mundo indígena del noroeste. Uno de los datos que así lo denotan es el de servicios en la vivienda, donde los indicadores muestran que la región Huicot (corahuichol-tepehuana-mexicanera) de Nayarit, Jalisco y Durango es la de mayor rezago en servicios a la vivienda de la república mexicana, seguidas de otros grupos (rarámuris, guarijíos, pimas), en la Sierra Madre Occidental, quienes ocupan el segundo lugar en rezago de servicios en viviendas (Instituto Nacional Indigenista [INI] 2001). ${ }^{21}$

Las diferencias en el noroeste respecto a condiciones de vida y de salud podemos ubicarlas asimismo en los análisis realizados por CDI-PNUD (2006) que utilizan los datos del XII Censo INEGI del 2000, los cuales reciben en esta fuente un manejo a escala estatal, municipal y por regiones indígenas. En el caso del noroeste se incluyen en este estudio 387 municipios de los nueve estados (donde hay presencia indígena al menos en 383) y tres regiones indígenas (Mayo-Yaqui, Huicot o Gran Nayar y Tarahumara). Desde esta perspectiva agregada, cabe señalar que la región Mayo-Yaqui presenta un índice de desarrollo humano (0.8324) más alto que el promedio nacional (0.8144), mientras que la región Huicot (0.6693) y la Tarahumara (0.6439) se situaron en los lugares 18 y 20 de las 25 regiones indígenas del país aquí

\footnotetext{
21 Por ejemplo, en el caso del agua, los estados con mayor carencia de agua entubada en zonas indígenas en el año 2000 fueron Durango (76.8 por ciento), Veracruz (76.7), San Luis Potosí (74.5); Chihuahua (66.1) y Nayarit (57.5). Por etnicidad la carencia de agua en la vivienda se documentó en tepehuanes (76.3 por ciento), tarahumaras (67.3), coras (66.1), tepehuas (64.3), pimas (63.8), totona$\cos$ (63.3), kanjobales (61.4), guarijíos (61) y huicholes (60.3) (Instituto Nacional Indigenista 2001).
} 
identificadas. En la elaboración de este índice se utilizaron cuatro indicadores: sobrevivencia infantil, alfabetismo, educación (asistencia escolar) e ingreso, La región Mayo-Yaqui quedó arriba del promedio nacional en los tres rubros, mientras que en el caso de la región Huicot el rubro más bajo fue el de sobrevivencia infantil, como también sucedió en la Tarahumara.

\section{Cuadro 5}

Índice de desarrollo humano indígena (IDHP) y no indígena en municipios del noroeste con más de 10 por ciento de población indígena e IDHP menor al promedio nacional, 2000

\begin{tabular}{|c|c|c|c|c|c|c|c|}
\hline \multirow{3}{*}{$\begin{array}{l}\text { Entidad } \\
\text { federativa }\end{array}$} & \multirow[t]{3}{*}{ Municipio } & \multicolumn{2}{|c|}{ Población } & \multirow{3}{*}{$\begin{array}{l}\text { \% de } \\
\text { población } \\
\text { indígena }\end{array}$} & \multirow{2}{*}{\multicolumn{3}{|c|}{$\begin{array}{l}\text { Índice de desarrollo } \\
\text { humano para los } \\
\text { pueblos indígenas }\end{array}$}} \\
\hline & & \multirow{2}{*}{ Total } & \multirow{2}{*}{ Indígena } & & & & \\
\hline & & & & & Indígena & $\begin{array}{c}\text { No } \\
\text { indígena }\end{array}$ & IDHPI \\
\hline Nayarit & Del Nayar & 26649 & 23123 & 86.8 & 0.5352 & 0.7541 & 0.5508 \\
\hline Chihuahua & Batopilas & 12545 & 6738 & 53.7 & 0.4636 & 0.7643 & 0.5479 \\
\hline Chihuahua & Carichí & 7760 & 3675 & 47.4 & 0.4781 & 0.7814 & 0.5564 \\
\hline Chihuahua & Morelos & 9482 & 2873 & 30.3 & 0.4503 & 0.7179 & 0.5808 \\
\hline Durango & Mezquital & 27512 & 20984 & 76.3 & 0.6435 & 0.7673 & 0.6170 \\
\hline Chihuahua & Balleza & 16770 & 8802 & 52.5 & 0.5387 & 0.8055 & 0.6207 \\
\hline Chihuahua & Urique & 17655 & 9442 & 53.5 & 0.5402 & 0.8326 & 0.6274 \\
\hline Chihuahua & Guachochi & 40615 & 28246 & 69.5 & 0.5832 & 0.8470 & 0.6332 \\
\hline Jalisco & Mezquitic & 14614 & 9747 & 66.7 & 0.5989 & 0.7893 & 0.6334 \\
\hline Chihuahua & Uruachi & 8282 & 2035 & 24.6 & 0.4997 & 0.7134 & 0.6356 \\
\hline \multirow[t]{2}{*}{ Chihuahua } & Guadalupe & & & & & & \\
\hline & y Calvo & 48355 & 17143 & 35.5 & 0.5217 & 0.7547 & 0.6367 \\
\hline Chihuahua & Guazapares & 8066 & 3040 & 37.7 & 0.5422 & 0.7532 & 0.6418 \\
\hline Nayarit & La Yesca & 12940 & 4424 & 34.2 & 0.5798 & 0.7475 & 0.6622 \\
\hline Jalisco & Bolaños & 5377 & 2760 & 51.3 & 0.6236 & 0.7421 & 0.6672 \\
\hline Chihuahua & Maguarichi & 1795 & 577 & 32.1 & 0.5875 & 0.7278 & 0.6716 \\
\hline Jalisco & Huajicori & 10294 & 2459 & 23.9 & 0.6122 & 0.7162 & 0.6879 \\
\hline Sinaloa & Elota & 49471 & 8044 & 16.3 & 0.5569 & 0.7581 & 0.7003 \\
\hline \multirow[t]{2}{*}{ Sonora } & San Miguel & & & & & & \\
\hline & Horcasitas & 5626 & 1061 & 18.9 & 0.6400 & 0.7522 & 0.7246 \\
\hline Sonora & Quiriego & 3335 & 365 & 10.9 & 0.6676 & 0.7382 & 0.7294 \\
\hline Chihuahua & Nonoava & 2946 & 506 & 17.2 & 0.6548 & 0.7568 & 0.7348 \\
\hline Chihuahua & Bocoyna & 27907 & 8818 & 31.6 & 0.6171 & 0.8343 & 0.7479 \\
\hline Jalisco & Ruíz & 21722 & 2892 & 13.3 & 0.6663 & 0.7726 & 0.7565 \\
\hline Sonora & Yécora & 6069 & 638 & 10.5 & 0.7042 & 0.7827 & 0.7715 \\
\hline Sinaloa & El Fuerte & 89515 & 12778 & 14.3 & 0.7244 & 0.7798 & 0.7719 \\
\hline Sonora & Etchojoa & 56129 & 23708 & 42.2 & 0.7339 & 0.8209 & 0.7822 \\
\hline Sonora & Bácum & 21322 & 2802 & 13.1 & 0.7308 & 0.7947 & 0.7841 \\
\hline \multirow[t]{2}{*}{ Sonora } & San Ignacio & & & & & & \\
\hline & Río Muerto & 13692 & 1952 & 14.3 & 0.7558 & 0.7967 & 0.7916 \\
\hline Sonora & Benito Juárez & 21813 & 2909 & 13.3 & 0.7634 & 0.8107 & 0.8037 \\
\hline Sonora & Huatabampo & 76296 & 18910 & 24.8 & 0.7474 & 0.8358 & 0.8088 \\
\hline Sonora & Navojoa & 140650 & 20769 & 14.8 & 0.7492 & 0.8428 & 0.8305 \\
\hline Sonora & Guaymas & 130329 & 15417 & 11.8 & 0.7249 & 0.8710 & 0.8474 \\
\hline
\end{tabular}

Fuente: elaboración propia con datos contenidos en CDI-PNUD (2006). 
En el ámbito de los nueve estados que aquí estamos considerando en nuestra definición del noroeste mexicano, nos interesa señalar que cinco de ellos muestran mejores condiciones para la población indígena al calcular un índice de desarrollo humano indígena, ubicando esta fuente a Coahuila, Baja California Sur, Jalisco, Baja California y Sonora dentro de niveles altos y medios-altos. Sin embargo, al observar las desigualdades entre los índices de desarrollo calculados para indígenas y no indígenas según esta misma fuente, hay que destacar que entre las entidades federativas, Chihuahua fue el estado que presentó la mayor variación interétnica (26.1 por ciento de diferencia entre el IDH de 0.6379 para indígenas y 0.8633 para no indígenas), seguido por Nayarit (21.6), Guerrero (20.9), Sinaloa (19.3), Chiapas (19), Durango (16.5), Puebla (15.4), Hidalgo (14.8), Baja California (11.8), Querétaro (11.7) y Sonora (11.2 por ciento). Es decir, aunque los indicadores muestran que — con la excepción de Nayarit, que se considera de desarrollo medio - las entidades federativas del noroeste pertenecen a las de mayor desarrollo humano; cabe señalar que en la mayoría de éstas existe una mayor desigualdad entre indígenas y no indígenas.

Desde luego, los grados de agregación estatal y por regiones indígenas ocultan la existencia de nichos indígenas con más bajos índices tanto de desarrollo como de equidad. Como puede observarse en el cuadro 5, entre los municipios que en el noroeste tienen más de un 10 por ciento de población indígena (31), hay grandes diferencias en el IDHPI (Índice de Desarrollo Humano de Pueblos Indígenas), incluyendo 17 municipios que muestran índices más bajos que el IDHPI nacional (0.7057, cuando entre la población no indígena fue de 0.8304 ) y 14 que lo superaron. Hay que notar que ninguno de los municipios con presencia indígena en el noroeste se ubica entre los de muy bajo desarrollo humano (hay 11 municipios en el país con un IDHPI menor de 0.500), mientras que en el ámbito de las regiones indígenas, la Huicot tiene dos municipios en un nivel bajo de desarrollo humano, uno de desarrollo medio y cinco de desarrollo medio-alto (no incluidos en el cuadro); la Tarahumara, tres de desarrollo bajo, seis de desarrollo medio y tres de nivel medio-alto, mientras que la Mayo-Yaqui de Sonora tiene cuatro de nivel medio-alto y cuatro de nivel alto.

Nuestros datos confirman estos hallazgos respecto a la heterogeneidad indígena en el noroeste, aun cuando nuestra metodología haya sido distinta, centrada en analizar los datos a partir de registros individualizados agrupados en definiciones ampliadas de la etnicidad, considerando aquí no solamente a los hablantes de alguna lengua indígena, sino también la autoadscripción étnica y la metodología de hogares indígenas. En cuanto al noroeste, la situación diferencial respecto a la salud y las condiciones de vida la podemos discernir anticipadamente del análisis de la cobertura de servicios 
básicos en viviendas, mediante el ejercicio de comparar los hogares indígenas con los no indígenas en situaciones rurales y urbanas o semiurbanas, como se muestra en las figuras 1 y 2 , donde aparecen datos emanados del cuestionario ampliado del XII Censo de 2000 del INEGI, basado en una muestra aplicada a 2.2 millones de hogares. Según podemos apreciar, en los tres estados del noroeste aquí analizados (Sonora, Chihuahua y Nayarit) la etnicidad es una condición relevante que se asocia a porcentajes menores de disponibilidad de servicios en las viviendas. Son amplias las brechas entre los hogares indígenas y los no indígenas, tanto en localidades menores como mayores de 2500 habitantes. Son ostensibles asimismo los contrastes entre rural y urbano, con diferencias entre los tres estados comparados, según el tipo de servicio analizado. En relación con las localidades más rurales, destaca la baja disponibilidad de agua en el interior de la vivienda, como también de drenaje. Es Chihuahua el estado que presenta los porcentajes más bajos concerniente al caso indígena, con un contraste muy marcado en el caso de las viviendas con electricidad.

En localidades más urbanas, de 2500 habitantes y más, Chihuahua es el estado que presenta mejores índices de cobertura, y aunque se repite la pauta de menores porcentajes en cuanto a viviendas habitadas por indígenas, en electricidad — a diferencia de lo que sucede en localidades francamente rurales - la cobertura es muy similar a la de los hogares mestizos (no

\section{Figura 1}

Porcentajes de cobertura de servicios en viviendas, Sonora, Chihuahua y Nayarit 2000. Localidades menores de 2500 habitantes

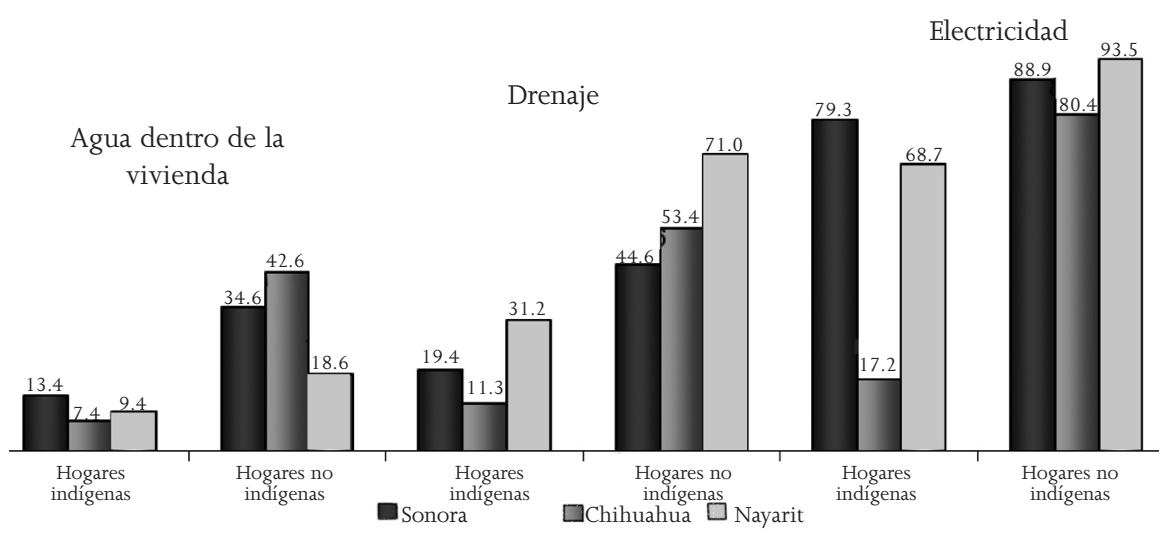

Fuente: elaboración propia con datos de INEGI. XII Censo General de Población y Vivienda 2000. 
indígenas). Sonora y Nayarit también repiten el patrón de cobertura menor de servicios en viviendas indígenas, siendo más evidentes los contrastes en los rubros de agua y drenaje. ¿Cuál puede ser la trascendencia para la salud de estos indicadores? En principio que constituyen hechos centinelas del grado de atención que el Estado brinda a estos núcleos poblacionales, debido a que representan —entre otros "mínimos de bienestar social”- demandas sociales frecuentes de encontrar tanto entre la población indígena como en la mestiza. Estas brechas y sus diferencias entre estados pueden de modo simultáneo relacionarse no solamente con la atención diferencial a las demandas de la población según su etnicidad, es decir, un factor de discriminación social, sino al mismo tiempo estar expresando las dificultades geográficas para la dotación de servicios entre población dispersa. Desde un punto de vista sanitario, estos índices a la vez merecen ser relativizados en el sentido de que disponer de agua dentro de la vivienda no garantiza su calidad, pero podemos suponer que al menos este hecho eleva la calidad de vida y garantiza mínimamente condiciones de higiene más accesibles, que son muy relevantes en la vida cotidiana y que explican en buena medida la más alta morbimortalidad que se presenta en regiones indígenas por enfermedades diarreicas y enteroparasitosis (Castro, Erviti y Leyva 2007; Guevara et al. 2003).

\section{Figura 2}

Porcentajes de cobertura de servicios en viviendas, Sonora, Chihuahua y Nayarit 2000. Localidades mayores de 2500 habitantes

$$
\text { Agua dentro de la }
$$
vivienda

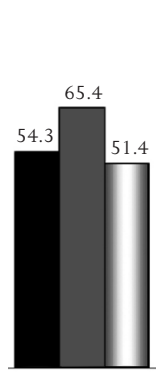
Hogares
indígenas Hogares
indígenas
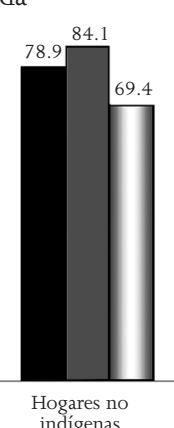
indígenas

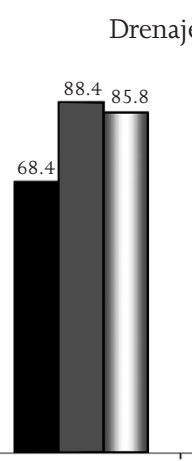

$$
\begin{gathered}
\text { Hogares } \\
\text { indígenas }
\end{gathered}
$$
indígenas

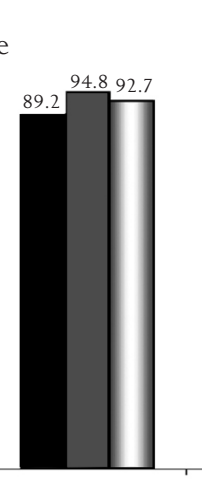

Hogares no indígenas
Electricidad

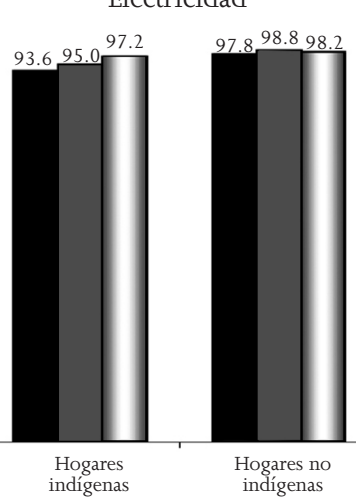

Sonora

Chihuahuall Nayarit

Fuente: elaboración propia con datos de INEGI. XII Censo General de Población y Vivienda 2000. Muestra censal. Registros ponderados. 
Lo mismo sucede respecto a la disponibilidad de drenaje. Es un hecho particularmente grave el bajo porcentaje de cobertura en hogares indígenas, puesto que en nuestro tratamiento de esta pregunta en el XII Censo estamos incluyendo diversas opciones además de la red pública, como es la fosa séptica y otras opciones nada sanitarias (tubería que va a dar a barrancas o fuentes de agua). En todo caso, hay que señalar que el fecalismo al aire libre es mucho mayor en los hogares indígenas muy rurales de Chihuahua, donde se constata además la mayor brecha (54.4 indígenas contra 14.5 por ciento no indígenas). La electricidad y la salud asimismo están vinculadas con el bienestar y la salud, en este caso con relación a la luz eléctrica en el domicilio, que permite mejores condiciones higiénicas; la posibilidad de conservar mejor los alimentos, de aliviar la inclemencia de los climas cálidos y una mayor accesibilidad a mensajes preventivos en radio y televisión.

Otros indicadores de desarrollo social que tienen influencia estrecha en la salud son el analfabetismo y el hablar solamente una lengua indígena sin tener dominio del idioma español. En el caso del primero, el porcentaje de población indígena que sabe leer y escribir es mejor en el noroeste si se compara con el nivel nacional (73.8 contra 69 por ciento, respectivamente), una pauta que se repite en los hogares no indígenas (91.5 por ciento en el noroeste y 89.3 en todo el país). Como sucede a escala nacional, los porcentajes de alfabetismo son más altos en la población no indígena y también el hecho de que se elevan a medida que aumenta el tamaño de población por localidad, siendo mayores las brechas entre indígenas y no indígenas en las localidades menores de 2500 habitantes. Y aunque el monolingüismo indígena es bajo en el noroeste (9.12 por ciento de los habitantes en hogares indígenas), hay que señalar que se concentra sobre todo en las localidades más rurales, donde alcanza a 14.5 por ciento de la población que habla alguna lengua indígena.

En cuanto al panorama de la derechohabiencia a instituciones públicas de salud, las pautas tienden a reproducir el escenario de los servicios a la vivienda, mostrando las entidades del noroeste mayor cobertura en servicios de salud que a escala nacional, pero presentando contrastes internos, por la condición rural o urbana y también según la etnicidad de los pobladores del noroeste mexicano, situaciones que influyen ampliamente sobre el derecho a servicios médicos. Según nuestro análisis del cuestionario ampliado del XII Censo, 80 por ciento de los indígenas mexicanos —en el ámbito nacional- (considerando hablantes de alguna lengua a aquellos que declararon sentirse indígenas) no tenían derecho a algún servicio médico en el 2000, en comparación con 55.3 por ciento entre los no indígenas. En el noroeste, en cambio, el porcentaje de indígenas sin derechohabiencia a alguna institución de salud fue de 60.8 por ciento y entre los no indígenas de 43.1. Al analizar 
estos datos por tamaño de localidad encontramos que en las localidades menores de 2500 habitantes fue mayor la proporción de población sin derechohabiencia, tanto en indígenas (71.8 por ciento) como en no indígenas (68.2), en contraste con las localidades mayores de 15 mil habitantes, donde los porcentajes respectivos fueron de 44.8 y 37.2 por ciento. Véase cuadro 6.

\section{Cuadro 6}

Derechohabiencia a seguro médico en el noroeste de México según tamaño de localidad, 2000

\begin{tabular}{|c|c|c|c|c|c|}
\hline $\begin{array}{l}\text { Tamaño de } \\
\text { localidad }\end{array}$ & Derechohabiencia & Indígenas & No indígenas & $\%$ indígenas & $\%$ no indígenas \\
\hline $\begin{array}{l}\text { Menor a } \\
2500 \\
\text { habitantes }\end{array}$ & $\begin{array}{l}\text { Derechohabiencia pública } \\
\text { Sin derechohabiencia } \\
\text { No sabe si tiene } \\
\text { derechohabiencia }\end{array}$ & $\begin{array}{r}94646 \\
277088 \\
13953\end{array}$ & $\begin{array}{r}1131674 \\
2556355 \\
\\
\quad 62743\end{array}$ & $\begin{array}{l}24.5 \% \\
71.8 \% \\
3.6 \%\end{array}$ & $\begin{array}{l}30.2 \% \\
68.2 \% \\
1.7 \%\end{array}$ \\
\hline $\begin{array}{l}2500 \text { a } \\
14999 \\
\text { habitantes }\end{array}$ & $\begin{array}{l}\text { Derechohabiencia pública } \\
\text { Sin derechohabiencia } \\
\text { No sabe si tiene } \\
\text { derechohabiencia }\end{array}$ & $\begin{array}{rl}43 & 427 \\
69 & 866 \\
1 & 011\end{array}$ & $\begin{array}{r}985585 \\
1236000 \\
27262\end{array}$ & $\begin{array}{l}38.0 \% \\
61.1 \% \\
0.9 \%\end{array}$ & $\begin{array}{l}43.8 \% \\
55.0 \% \\
1.2 \%\end{array}$ \\
\hline 15 mil y más & $\begin{array}{l}\text { Derechohabiencia pública } \\
\text { Sin derechohabiencia } \\
\text { No sabe si tiene } \\
\text { derechohabiencia }\end{array}$ & $\begin{array}{r}163927 \\
137827 \\
5758\end{array}$ & $\begin{array}{l}9074006 \\
5506857 \\
216575\end{array}$ & $\begin{array}{r}53.3 \% \\
44.8 \% \\
1.9 \%\end{array}$ & $\begin{array}{l}61.3 \% \\
37.2 \% \\
1.5 \%\end{array}$ \\
\hline
\end{tabular}

Fuente: elaboración propia. Cuestionario ampliado XII Censo INEGI, registros ponderados.

¿Qué tanto se ha modificado este panorama a raíz de la introducción del Seguro Popular? La ENSANUT 2006 incluyó esta opción en las respuestas a la pregunta “¿Está afiliado o inscrito a algún seguro médico?”. Del análisis de las respuestas a la pregunta se desprende que en el conjunto de los nueves estados del noroeste no existen brechas tan pronunciadas entre indígenas y no indígenas, donde poco más de la mitad de la población en general cuenta con algún tipo de seguro médico. En Sonora, la población indígena muy rural (en localidades menores de 2500 habitantes) mostró incluso una mayor derechohabiencia (75 por ciento) respecto tanto a los mestizos del mismo medio rural como a la población urbana (en localidades mayores de 2500 habitantes), según se muestra en la figura 3 y el cuadro 7.22

22 La Encuesta Nacional de Salud y Nutrición 2006 (ENSANUT) forma parte de una serie de encuestas de este tipo que se han realizado en el país desde 1986; contienen información sobre nutrición pre- 


\section{Figura 3}

Afiliación a algún tipo de seguro médico-ENSANUT 2006

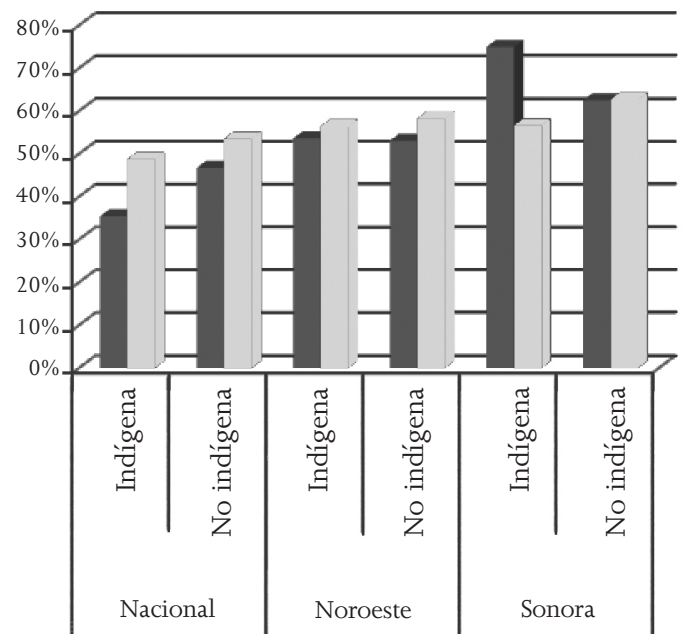

Porcentaje de asegurados en localidades de menos de 2500 habitantes

Porcentaje de asegurados en localidades de más de 2500 habitantes

Fuente: elaboración propia con datos de la ENSANUT 2006 (pregunta 2.08 del cuestionario hogar).

\section{Cuadro 7}

Afiliación a algún tipo de seguro médico-ENSANUT 2006

\begin{tabular}{|l|c|r|r|r|r|r|r|}
\hline \multirow{2}{*}{$\begin{array}{l}\text { Nivel de } \\
\text { análisis }\end{array}$} & $\begin{array}{c}\text { Respuestas } \\
\text { de todos los } \\
\text { miembros } \\
\text { del hogar }\end{array}$ & \multicolumn{2}{|c|}{ Zona rural (-2 500 habs) } & \multicolumn{3}{|c|}{ Zona urbana (+2 500 habs) } \\
\cline { 3 - 8 } & encuestados & $\begin{array}{c}\text { N con } \\
\text { seguro } \\
\text { médico }\end{array}$ & $\begin{array}{c}\text { \% con } \\
\text { seguro } \\
\text { médico }\end{array}$ & $\begin{array}{c}\text { N } \\
\text { encuestados }\end{array}$ & $\begin{array}{r}\text { N con } \\
\text { seguro } \\
\text { médico }\end{array}$ & $\begin{array}{c}\% \text { con } \\
\text { seguro } \\
\text { médico }\end{array}$ \\
\hline Nacional & Indígena & 18250 & 6456 & $35 \%$ & 24882 & 12132 & $49 \%$ \\
& No indígena & 38264 & 17856 & $47 \%$ & 125303 & 67067 & $54 \%$ \\
\hline Noroeste & Indígena & 2651 & 1420 & $54 \%$ & 5236 & 2954 & $56 \%$ \\
& No indígena & 10160 & 5386 & $53 \%$ & 37526 & 21851 & $58 \%$ \\
\hline Sonora & Indígena & 283 & 212 & $75 \%$ & 948 & 537 & $57 \%$ \\
& No indígena & 661 & 413 & $62 \%$ & 4157 & 2605 & $63 \%$ \\
\hline
\end{tabular}

Fuente: elaboración propia con datos de la ENSANUT 2006 (pregunta 2.08 del cuestionario hogar).

valencia de enfermedades crónicas, infecciosas y gasto catastrófico. La ENSANUT tiene representación a escala nacional y en las entidades federativas; recaba información en 48304 hogares y de 206700 individuos de todas las edades (integrantes de hogar). Aunque no se abordó el tema de la salud indígena de forma amplia, la encuesta contiene un par de preguntas que nos permitieron construir indicadores de etnicidad. Al combinar ambas preguntas se elaboró una variable de etnicidad, la cual se utilizó para hacer cruces con el resto de los indicadores sanitarios. Dicho indicador nos dice si el individuo en la encuesta contesta afirmativamente a cualquiera de las dos preguntas (autoadscripción y hablante de alguna lengua indígena). Por desgracia, la base de datos sólo permitió realizar el análisis según tamaño de localidad en las categorías de menor y mayor de 2500 habitantes (Instituto Nacional de Salud Pública 2006). 
No obstante que la situación indígena en derechohabiencia es menos desfavorable en el noroeste mexicano con respecto al ámbito nacional, es necesario relativizar estos datos en relación con la cobertura diferenciada que ofrecen estos seguros médicos, siendo en el caso del Seguro Popular un modelo de derechohabiencia muy limitado en comparación con el resto de opciones públicas y privadas, aunque consideramos que efectivo para resolver problemas del primer nivel de atención y en forma parcial del segundo y menos del tercero.

En el noroeste de México las diferencias étnicas en materia de salud se encuentran estrechamente ligadas al grado de dispersión poblacional y la inaccesibilidad geográfica de los asentamientos indígenas, un hecho atribuible a la condición de "región de refugio" (Aguirre Beltrán 1967) en la que subsisten algunos colectivos étnicamente diferenciados, pero que contrasta con la situación en que se hallan otros grupos e individuos que habitan en localidades mayores de 2500 habitantes o que al menos se encuentran relativamente bien comunicados mediante vías terrestres de transporte, lo cual se correlaciona asimismo con el grado de aculturación que presenta cada grupo en lo particular, la persistencia del monolingüismo y analfabetismo y el acceso a servicios básicos de la vivienda o a los servicios de salud. Son estos rubros en los que en particular muestran desventajas ostensibles respecto a colectivos indígenas que viven en ciudades, pero también contrastes elocuentes cuando se comparan algunos indicadores con los de los habitantes no indígenas de localidades tanto rurales como urbanas. No obstante, es importante contextualizar estas aseveraciones, adelantando que esto depende no sólo de las grandes agrupaciones a nivel macrorregional (noroeste), sino que varían de acuerdo con las entidades federativas, en las cuales encontramos distinciones relevantes respecto a la cobertura de servicios y también en el perfil epidemiológico, siendo, por ejemplo, muy distinto el panorama en Sonora al que se presenta en otros estados que también podemos considerar del noroeste, como Chihuahua y Nayarit.

\section{Hacia una epidemiología sociocultural de la salud indígena en México y el noroeste mexicano}

¿Qué tan diferentes son las condiciones de vida y de salud de los indígenas rurales en contraste con los pobres del campo? Debemos señalar que no tenemos una respuesta precisa para contestar esta pregunta en forma generalizable, por cuanto nuestra exploración — tanto documental como también en el análisis de las bases de datos_ nos ha demostrado que las situaciones 
son heterogéneas para el conjunto de los pueblos indígenas del país; según su condición rural-urbana y también en las condiciones diferenciadas para los distintos grupos étnicos, como se desprende de la indagación más específica sobre los pueblos del noroeste mexicano. Es evidente que la comparación de indígenas y no indígenas, distinguiendo su ubicación según tamaño de localidad (menor y mayor de 2500 habitantes), nos muestra brechas importantes en ciertos indicadores epidemiológicos y de atención a la salud, siendo la pauta general a escala nacional una situación más desfavorable para los habitantes rurales y aún más para los colectivos indígenas. No obstante, esto depende de los indicadores sobre los cuales enfoquemos nuestra mira, pero también de las tendencias que pueden apreciarse. Desde esta perspectiva, una conclusión general es que los pueblos indígenas están enfrentando una transición demográfica, epidemiológica y quizás de atención a la salud en condiciones de rezago respecto al resto de la población mexicana, lo cual es particularmente evidente en el nivel de las localidades rurales y no tanto en las urbanas. Y que existen indicios de que especialmente entre los grupos serranos el problema del subregistro es aún importante y puede estar ocultando altos índices de mortalidad infantil y materna como de otras causas evitables. Así nos lo sugiere nuestra propia experiencia de trabajo en la región guarijía (Haro et al. 1998), como también la revisión de algunos reportes de base etnográfica entre los pimas bajos (Hope 2006), los tarahumaras (Mull y Mull 1985), los huicholes (Guzmán 2004), los seris (Luque y Robles 2006), los yaquis (Luna 2007) e incluso los yumanos de Baja California, quienes tienen un contacto más intenso con la sociedad circundante (Fleuriet 2003).

A la vez los indígenas manifiestan también problemas emergentes de salud como consecuencia de una "modernización defectuosa" (Simonelli 1987), que se expresan en los rubros de varias enfermedades crónico-degenerativas, adicciones, problemas de salud mental, alcoholismo (quizás no tan emergente en ciertos grupos étnicos pero actualmente a base de bebidas industrializadas), accidentes, diferentes tipos de cáncer y también problemas de intoxicaciones agudas y crónicas derivadas de los cambios en la producción agrícola (Cartwright 2001, Díaz Romo y Salinas 2002). Un problema particularmente importante por la proclividad genética indígena es el del síndrome metabólico, como lo muestran ciertos indicios de que hay quizás una mayor prevalencia de diabetes y obesidad entre indígenas (Bennet, Rushforth y Miller 1976; Valencia et al. 1999; Schulz et al. 2006,), especialmente para quienes sus condiciones actuales han significado un brusco cambio de vida, como sucede por ejemplo con los comcáac o seris, los grupos yumanos y también los indígenas de residencia urbana en lo general. Lejos de considerar que los problemas que surgen son elecciones personales o 
familiares habría que asumir que en la adopción de estilos de vida no saludables influyen de manera importante efectos diversos del despojo territorial, la subordinación obligada a procesos que vienen del exterior y la discriminación en el ámbito local y también en el regional.

En el campo de atención a la salud encontramos también indicios diferenciales que ilustran la heterogeneidad de situaciones. No son datos concluyentes ni generalizables, debido a la falta de representatividad estadística. Pero son congruentes con información emanada de diversas fuentes, en el sentido de que la introducción de diversas estrategias, como son el Seguro Popular, el IMss-Oportunidades y el Programa Oportunidades (antes Progresa), han modificado quizás el panorama de ciertos rubros críticos, como la atención prenatal, la atención obstétrica, la detección oportuna de cáncer cervicouterino, un hecho que observamos más en las entidades del noroeste analizadas que en el conjunto de los estados de la república; los indígenas rurales aparecen con mejores indicadores en varios de estos rubros que los mestizos, tanto urbanos como rurales. También es preocupante la no correlación entre derechohabiencia asumida y uso del servicio correspondiente en la atención del último problema de salud, lo cual encontramos referido, aun sin ser nuestro análisis lo suficientemente detallado, especialmente en el caso del Seguro Popular, hecho que atribuimos a la cobertura selectiva y limitada de atención a los problemas de salud.

Abordar el panorama de la salud y su relación con las condiciones de vida entre los pueblos indígenas de esta región requiere, a nuestro ver, advertir de entrada la relatividad que puede adquirir este ejercicio respecto a la confiabilidad que ofrecen los datos numéricos obtenidos mediante cuestionarios estandarizados; también respecto a los referentes culturales de los cuales partimos, indicando que éstos pueden ser etnocéntricos, aunque no por ello menospreciables. ¿Por qué señalamos esto? Para nosotros es una reflexión necesaria que surge de ciertas incongruencias encontradas en las respuestas obtenidas a través de las bases de datos que trabajamos (XII Censo del INEGI y Encuesta Nacional de Salud y Nutrición 2006) y nuestras propias experiencias de campo, relativas en este caso a la alteridad cultural que se mantiene vigente entre los pueblos indígenas de esta región del país, acostumbrados a preservar una nítida separación entre lo propio y lo ajeno, y que en el caso de la salud adquiere una particular vigencia al ser un tema estrechamente relacionado con la cosmovisión cultural, marcada por una profunda y proverbial desconfianza hacia todo aquello que viene etiquetado como parte del mundo de los blancos ("yoris" para los cahitas, "chabochis" para los rarámuri, y en gran parte de las mitologías sobre los orígenes, hijos del diablo).

Un ejemplo de estas incongruencias, quizás también relativo a la escasez de suficientes casos étnicamente referenciados, lo encontramos en la baja 
morbilidad reportada en síndromes delimitados culturalmente (susto, empacho, mal puesto), como también al escaso uso de recursos de la medicina tradicional, particularmente la consulta a curanderos y yerberos, lo cual descubrimos en una de las bases de datos analizadas (ENSANUT 2006) por parte de los indígenas encuestados. Es un hecho que contrasta con los hallazgos etnográficos propios y ajenos, que destacan la alta atribución sobrenatural a enfermedades comunes que son reconocidas por la medicina occidental, su traslape con los llamados síndromes de filiación cultural y la combinación amplia y casi sistemática de recursos de la medicina occidental con los de la autoatención y de la medicina tradicional (Zolla 2003), un hecho que hemos testimoniado regularmente en nuestras estancias tanto con los mahkurawe (guarijíos) como con los yoemes (yaquis) del sur de Sonora. ${ }^{23}$ No obstante esta advertencia, también debemos relativizar este relativismo y considerar que hay datos cuantitativos que hemos explorado y que evidencian claramente las condiciones diferenciales que caracterizan a los colectivos indígenas. Todo depende de distinguir aquellos datos que son culturalmente sesgados; es la etnicidad misma la primera cuestión importante para nuestro análisis.

En el caso de nuestra alteridad cultural con respecto a las situaciones exploradas, cabe advertir que nuestra posición no implica el abandono de los indicadores convencionales de salud (mortalidad, agua, drenaje), sino todo lo contrario: el ampliar nuestra perspectiva epidemiológica más allá de lo aceptado por el campo biomédico, en el sentido de considerar que más que una noción de salud basada en referentes estrictamente biológicos, lo que se requiere al evaluar la salud de los pueblos indígenas atañe a una ampliación de la mirada que quizás nos conduzca, de un concepto de salud fundamentado en la no enfermedad o en el mejoramiento de la esperanza de vida o del nivel nutricional, hacia un concepto indígena de equilibrio y armonía, que alude a las relaciones interpersonales, a las relaciones con el entorno físico y social (no indígena, en el sentido de superar los abusos de poder y la discriminación) y especialmente a la facultad de la autonomía, de la no subordinación. Éste es claramente un reto al cual una epidemiología sociocultural tiene mucho que aportar, en el diálogo permanente con los destinatarios de los servicios, los programas, las políticas. Más aún, exige un ejercicio dialógico con

\footnotetext{
23 A la vez nos interesa señalar las limitaciones de las encuestas revisadas respecto a la reducción de posibilidades. En el cuestionario ampliado del XII Censo, por ejemplo, se pregunta: "cuando tiene problemas de salud, ¿dónde se atiende?”, como si pudiera distinguirse una pauta única para todos los episodios de enfermedad. En la ENSANUT 2006 (INSP 2006), a su vez, se pregunta a las mujeres que tuvieron algún hijo en los últimos cinco años: “quién y cuántas veces la revisó durante el embarazo?”. Existen seis opciones de respuesta (médico, enfermera, promotora, partera, otro personal o nadie), pero sólo se permite al encuestador anotar dos de ellas.
} 
las comunidades indígenas en el cual puedan debatirse los hallazgos de investigación en un marco netamente intercultural y participativo.

Desde una perspectiva crítica, una de las conclusiones más evidentes de nuestro ejercicio es la relativa a la precariedad de la información con la que contamos, lo cual no se deduce solamente de la escasez de datos, sino también de la inespecificidad que revisten al ser cotejados tanto con lo publicado como con nuestra propia experiencia de campo. ¿Por qué señalar esto? En primer término, porque la heterogeneidad de situaciones que se desprende del análisis de la salud indígena, en nuestro caso referida al noroeste de México, es indicativo de la necesidad de particularizar el análisis, no sólo respecto al grupo étnico específico (lo cual implica preguntar si el encuestado se siente indígena, pero asimismo que se especifique de qué grupo étnico se considera miembro), sino también a la distinción de situaciones en las que los colectivos étnicos están actualmente insertos (rural-urbano o suburbano, en campos agrícolas o en territorios tradicionales). Además, es muy relevante que se juzgue la etnicidad de cada grupo indígena como un criterio a tomar en cuenta en el muestreo en relación con la representatividad que debería mantener cada grupo étnico en su aplicación regional o estatal. Ésta fue nuestra experiencia con el manejo de la ENSANUT 2006, cuyos resultados pierden representatividad al ser desagregados tanto respecto al tamaño de localidad que permite la fuente (menor o mayor de 2500 habitantes) como en nuestro intento de distinguir la condición étnica a nivel de los estados, siendo para el caso de algunos indicadores muy escasas las respuestas obtenidas.

A pesar de estas limitantes, consideramos que el análisis efectuado nos permite sustentar varios hallazgos generales, sin dejar de subrayar la necesidad de particularizar con miras a situar una especie de línea basal para evaluar el impacto de las intervenciones. En primer término, el señalar que es evidente que tanto en el ámbito nacional como en el del noroeste la población indígena muestra condiciones de salud y de atención a ésta que son en lo general desfavorables cuando las comparamos con las condiciones de la población mestiza, ya sea rural o urbana. Es verdad que en el noroeste las diferencias tienden a ser menos desfavorables que en el contexto nacional, como también que la brecha entre indígenas y no indígenas, al igual que entre habitantes rurales y urbanos, tiende a ser menos marcada. Por ello, un segundo punto se refiere a la distinción del noroeste mexicano como un espacio que ofrece un perfil epidemiológico distinto al del nivel nacional, encontrando además heterogeneidad en las situaciones analizadas de acuerdo con la etnicidad y residencia de sus pobladores según tamaño de localidad.

También hemos podido explorar, aunque sea de manera muy incipiente, las diferencias existentes entre las tres entidades federativas que hemos ana- 
lizado por separado, encontrando contrastes significativos entre las situaciones que viven especialmente los indígenas rurales cuando comparamos su situación en Sonora, Chihuahua y Nayarit, por lo que el manejo agregado de los datos puede estar ocultando situaciones muy diferenciales. Aunque la información obtenida es elocuente, es necesario aún hacer un esfuerzo por referenciar étnicamente esta información de acuerdo con la situación específica de cada grupo indígena en particular, desde la perspectiva de que en esta información antes presentada se encuentran no solamente amalgamados los distintos grupos autóctonos del noroeste mexicano, sino también importantes cuotas de indígenas inmigrantes que se hallan sumados en este panorama presentado, lo cual mantiene una importancia relativa, debido a que todos estos grupos étnicos comparten en buena medida ciertas situaciones comunes derivadas de su alteridad étnica. Hace falta alcanzar una mayor profundidad en el manejo de los datos, pero por razones de limitación temporal no fuimos capaces de lograrlo. Un ejemplo de ello sería el distinguir los datos sobre atención a la salud en el último episodio de enfermedad (ENSANUT 2006) conforme a distintas condiciones patológicas.

Independientemente de la etnicidad específica de los encuestados e incluso de la falta de representatividad de los datos, resulta al menos elocuente que la mayoría de los indicadores sobre salud materno-infantil sean mejores para la población indígena - tanto rural como urbana- en el noroeste con respecto al nivel nacional, siendo también congruente que éstos empeoren cuando comparamos el nivel noroeste con lo que sucede en Nayarit y Chihuahua, pero no respecto a Sonora, donde tendieron a ser mucho mejores. Tendríamos que llevar a cabo estudios más detallados para indagar si es verdad que en este estado la situación de la salud maternoinfantil es mejor en el medio indígena, incluso al establecer comparaciones con la población mestiza. Es muy probable que sea un sesgo derivado de la escasez de casos registrados para algunas de las preguntas, pero resulta coherente con información generada por otros medios, la que muestra que la salud materno-infantil es un grave problema tanto en la región Tarahumara como en la Huicot. A la vez, los más altos porcentajes de mujeres indígenas y mestizas del medio rural que se realizaron el papanicolau respecto a las urbanas indígenas y mestizas puede ser un vestigio del impacto de Oportunidades en el medio indígena y rural.

Lo que nos interesa destacar no son tanto las diferencias en materia de salud que surgen al comparar a la población indígena con el resto de la población nacional, algo que ha sido demostrado reiteradas veces. No obstante, como ya hemos señalado antes, al rezago epidemiológico se suman en la actualidad pautas aculturadoras que indican la combinación de las enfermedades de la pobreza con entidades patológicas subsecuentes a la acultura- 
ción, habiendo evidencias de ello tanto en nuestros análisis de las bases de datos como en los reportes etnográficos revisados. En buena medida los cambios culturales se asocian a la adopción de pautas alimentarias que son nocivas para la salud, como es el caso de los refrescos embotellados, las bebidas alcohólicas industrializadas y los alimentos llamados "chatarra”, los cuales implican reacomodo - pero no pérdida - de la identidad étnica (véase el caso de los comcáac en Gómez Zavala 2005). Sin embargo, esto no obedece sólo a la introducción de estos productos en los mercados locales, sino de igual modo a la pérdida de alimentos tradicionales ocasionada por numerosos cambios ecológicos, así como por la adopción de pautas migratorias y cambios productivos. Asimismo, la penetración de las siembras de estupefacientes, donde las regiones indígenas mantienen una vocación productiva debido a la condición de muchas de ellas como "regiones de refugio", ha traído una dinámica inédita en la vida cotidiana de ciertas poblaciones indígenas. La condición de aislamiento y lejanía de los centros rectores tiene como consecuencia también una pobre dotación de servicios a las viviendas, siendo el agua y el drenaje una de las condiciones críticas que se asocian a pobres niveles de higiene y la proliferación de enfermedades transmisibles. También sucede con el acceso a servicios de salud, con pautas de cobertura en lo general más bajas para indígenas rurales. Un factor que consideramos de mucho peso lo constituye el destinar estas comunidades para ser atendidas por médicos pasantes en servicio social, cuando bien sabemos que la atención intercultural requiere de un prolongado tiempo de adaptación y capacitación local.

Desde nuestra propia experiencia en el terreno de la atención a la salud indígena conocemos al menos tres factores críticos que pueden explicar diferencias en los perfiles epidemiológicos y de atención a la salud entre indígenas y mestizos rurales. Uno de ellos es el factor cultural, que aquí asociamos a formas diferenciales de concebir los eventos de salud, relacionado con la existencia de un sistema de creencias. No obstante, no contamos con estudios específicos que nos permitan ponderar su importancia respecto a las diferencias epidemiológicas ni en cuanto a pautas de atención. En ocasiones sabemos que puede operar como un factor de retardo en la búsqueda de atención a la salud o también en la no recepción de consejos preventivos. Las explicaciones de la medicina tradicional pueden ser consideradas antagónicas a las de la medicina occidental, la cual puede verse como algo ajeno o más bien lejano, tanto en un sentido geográfico como cultural, como fuente de malos tratos o de difícil acceso. Los factores culturales a la vez se relacionan estrechamente con la competencia lingüística de los grupos indígenas, refiriéndonos en este caso no tanto a la condición bilingüe que se atribuye a la mayoría de los indígenas, sino al grado de competencia bilingüe, como el 
manejo de vocabulario, el cual suele ser desfavorable debido a un menor grado de contacto con la sociedad nacional. Igualmente los factores culturales operan en el ámbito de la salud siguiendo pautas de relaciones de género y de grupos generacionales étnicamente referenciadas. No obstante, según nuestros hallazgos la imagen más cercana a la realidad es que la mayoría de los indígenas hace un uso pragmático de recursos terapéuticos de diverso sino, y que el acudir a un curandero no implica que no se acuda a la medicina alopática, o viceversa.

El acceso desfavorable a la información y también mayores cuotas de analfabetismo y escolaridad entre los indígenas respecto a la población mestiza tiene como consecuencia que muchas de estas causas se encuentren amalgamadas con el aislamiento propio de situaciones muy rurales, donde concurren además factores de baja cobertura y acceso a los servicios, de transporte ineficiente y de carencia de suficientes medios económicos y facilidades laborales, que son eminentemente sociales y no netamente culturales. Esto se relaciona con un segundo factor, que es la discriminación étnica, la cual opera en forma "intersticial” en las regiones interculturales, manifestándose de forma a veces sutil respecto al manejo de información, el acceso a oportunidades laborales u otras de superación, la exclusión y la autoexclusión de procesos vindicativos, etcétera. Estos y otros factores de conflicto emergen en las situaciones interculturales y en ocasiones se relacionan con un tercer factor que interesa aquí resaltar: las desigualdades en los apoyos recibidos desde el exterior, entre los cuales hay que destacar los relativos a la acción indigenista, la que ha tendido a concentrarse predominantemente en la población indígena, excluyendo a la mestiza pobre y rural. Lo señalamos porque para los mestizos locales, el apoyo diferencial suele aumentar en ocasiones la exclusión de los indígenas de otras fuentes de apoyo y solidaridad. No obstante, cabe señalar que según nuestras investigaciones en la región guarijío de Sonora, a pesar de los apoyos recibidos, los indígenas presentaron peores condiciones de salud respecto a los mestizos pobres de esa misma región (Haro et al. 1998). Esto se explica porque los programas tanto federales como estatales tienden a concentrarse a nivel local en poblaciones sobre todo mestizas. La desinformación, el nepotismo, los efectos subrepticios de la discriminación operan en las regiones interculturales con selectividad en los apoyos a favor de los mestizos. El aislamiento de muchas familias indígenas asume formas que no son sólo deducibles de factores físicos sino también socioculturales.

Otros factores que nos parecen relevantes para evaluar la salud rural, indígena y mestiza, los cuales señalamos con base en tres fuentes: el análisis de datos de la ENSANUT 2006 y el XII Censo, nuestra experiencia de campo y la revisión documental. El tamaño de la localidad debe considerarse contex- 
tualmente, pues no es lo mismo vivir en una comunidad pequeña en condiciones de aislamiento geográfico y orografía escarpada que habitar en localidades que, a pesar de ser pequeñas, están bien comunicadas con centros poblacionales más grandes. No obstante, aun sin haber realizado esta distinción en nuestro análisis, es primordial reconocer que en México las localidades menores de 2500 habitantes presentan en lo general coberturas de servicios que suelen ser desfavorables, acompañándose de mayores índices de rezago sanitario. La densidad étnica es otro factor importante, que alude a la forma en que determinadas familias indígenas viven en situaciones que potencialmente pudieran asegurar una mayor disponibilidad de redes sociales o de reproducción cultural, como a la vez relacionarse este aspecto con la posibilidad de discriminación o con mayores recursos de información. Sin embargo, no debemos creer que este factor opera automáticamente en forma positiva. Hemos de cuidarnos de la influencia de los estereotipos, de seguir la tendencia a considerar como homogénea a una cultura que no lo es en la realidad. Esto nos lleva a un tercer factor relevante, que es la cultura sanitaria en el seno familiar. Según nuestra experiencia entre los grupos indígenas, hay mucha variación al respecto, que se deriva de tradiciones familiarmente heredadas y también de distintos grados de contacto y experiencia con la cultura mestiza o con el personal de salud.

Obviamente, la presencia de servicios de salud en la localidad o en su cercanía es un factor muy relevante, que debe ser visto también con cuidado, señalando que el grado de cobertura del servicio, su costo, la accesibilidad geográfica y cultural, y, muy importante, la calidad del personal que atiende estos servicios de salud, son todos ellos determinantes. El abasto de recursos y otros factores de la calidad de la atención son desde luego significantes, como lo es también por su trascendencia económica y de dinámica relacional la existencia de discapacitados o enfermos crónicos en el hogar. Incluimos aquí también la consideración de los recursos de la medicina tradicional, advirtiendo críticamente que su eficacia o ineficacia no debe ser evaluada sin conocerla. Es lo que ocurre, por ejemplo, con parteras y sobadores o yerberos, buena parte de ellos recursos humanos experimentados y en algunos casos capacitados. La distancia también debe relativizarse, tomando en cuenta las condiciones locales y la existencia de transportes adecuados, incluyendo semovientes, vehículos de motor, etcétera. La marginación, en cuya definición intervienen el ingreso económico y también los servicios en viviendas, es otro factor muy relevante para el cuidado de la salud, encontrando en nuestra revisión numerosas evidencias de ello. Deben tenerse presente también en esta relación las características de las familias, como son el índice de dependencia económica, la fase del ciclo vital, la fuente y el monto de los ingresos. En las regiones indígenas es muy importante no dejar de lado 
lo concerniente a la recepción de remesas por parte de miembros migrantes o los ingresos por actividades en el narcotráfico, que no son nada excepcionales en regiones indígenas especialmente serranas. También afirmamos, con base en la revisión de la literatura, que tanto la condición de la competencia lingüística como el grado de escolaridad son factores posiblemente fundamentales para el cuidado de la salud. No obstante, también es presumible que se relacionan contextualmente en el nivel local, dependiendo de la cultura en materia de salud familiar, la capacitación intercultural del personal sanitario y la existencia de redes sociales competentes.

Para un ejercicio epidemiológico sociocultural resulta importante no sólo precisar con mayor detalle la información cuantitativa, incluyendo el criterio de etnicidad, sino también contextualizar esta información en la comparación con referentes significativos, como puede serlo en este caso la población local o regional no indígena. Además, es esencial explorar las situaciones indígenas mediante el recurso de la etnografía, especialmente si lo que se pretende es elaborar un diagnóstico de salud que sirva como base para la planeación y evaluación de intervenciones en el campo de la salud pública. En este marco, la interrelación de los recursos para la salud existentes, las estrategias locales de acción y el ámbito de las relaciones y las representaciones sociales sobre los eventos de salud resultan ser cruciales para diseñar programas y políticas específicas. También la participación de las comunidades indígenas en los procesos de diagnóstico, diseño de programas, implementación y su evaluación. Consideramos que la investigación efectuada en el presente trabajo nos muestra la necesidad de un abordaje más especializado, en el marco de lo que nosotros proponemos como una tarea para la epidemiología sociocultural.

\section{Bibliografía}

Aguirre Beltrán, Gonzalo. 1967. Regiones de refugio. El desarrollo de la comunidad y el proceso dominical en Mestizoamérica. México: Instituto Indigenista Interamericano.

American Association of Physical Anthropology. 1996. AAPA Statement on Biological Aspects of Race. American Journal of Physical Anthropology 101: 569570 .

Asamblea Nacional Indígena Plural por la Autonomía. 1997. Los indígenas en México. Reforma. 12 de septiembre. 
Banton, Michael. 1967. Race Relations. Londres: Tavistock.

Barbujani, Guido, Arianna Magagni, Eric Minch y Luigi Luca Cavalli-Sforza. 1997. An Apportionment of Human DNA Diversity. Proceedings of the National Academy of Sciences USA 94: 4516-4519.

Barth, Friederich. 1976. Los grupos étnicos y sus fronteras. México: Fondo de Cultura Económica.

Bassols Batalla, Ángel. 1972. El noroeste de México. Un estudio geográfico-económico. México: Universidad Nacional Autónoma de México, Instituto de Investigaciones Económicas.

Beals, Ralph L. 1974 [1943]. Relations between Mesoamerica and the Southwest. En Basil C. Hedrick, J. Charles Kelley y Carroll L. Riley. The Mesoamerican Southwest. Readings in Archeology, Ethnohistory and Ethnology, 58-63. Carbondale: Southern Illinois University Press.

Bennett, Peter H., Norman B. Rushforth y Max Miller. 1976. Epidemiological Studies of Diabetes in the Pima Indians. Recent Program in Hormone Research 32: 333-376.

Bhopal, Raj y Liam J. Donaldson. 1998. White, European, Western, Causasian, or What: Inappropriate Labeling in Research on Race, Ethnicity, and Health. American Journal of Public Health 88 (9): 1303-1307.

Blanco Muñoz, Julia, Rosalinda Hernández Muñoz, Ana Luisa Montiel Cervantes, Lourdes Huerta Pérez, Silvia Medina Corona, Marina Ojeda Velázquez, Aurelio Cruz Valdez, Francisco José Dubón Tomé, María Lilia Rodríguez Martínez, Julia Recio Pérez, Escuela de Salud Pública de México, Instituto Nacional de Salud Pública. 1994. Mortalidad materna en el área huichol del estado de Jalisco, México. Salud Pública de México 36 (3): 263-268.

Bonham, Vence L., Esther Warshauer-Baker y Francis S. Collins. 2005. Race and Ethnicity in the Genome Era: the Complexity of the Constructs. American Psychologist 60 (1): 1-9.

Bradby, Hanna. 2003. Describing Ethnicity in Health Research. Ethnicity and Health 8 (1): 5-13. 
Burchard, Esteban, Elad Ziv, Nathasha Coyle, Scarlett L. Gómez, Hua Tang, Andrew J. Karter, Joanna L. Mountain, Eliseo J. Pérez-Stable, Dean Sheppard y Neil Risch. 2003. The Importance of Race and Ethnic Background in Biomedical Research and Clinical Practice. New England Journal of Medicine 348 (12): 1170-1175.

Byrkit, James W. 1992. Land, Sky, and People: The Southwest Defined. Journal of the Southwest 34 (3): 257-387.

Cartwright, Elizabeth. 2001. Espacios de enfermedad y sanación. Los amuzgos de Oaxaca. Entre la sierra sur y los campos agrícolas de Sonora. Hermosillo: El Colegio de Sonora.

Castro, Roberto, Joaquina Erviti y René Leyva. 2007. Globalización y enfermedades infecciosas en las poblaciones indígenas de México. Cadernos de Saúde Pública 23 (1): S41-S50.

Cavalli-Sforza, Luigi L., Alberto Piazza, Paolo Menozzi y Joanna Mountain. 1988. Reconstruction of Human Evolution; Bringing together Genetic, Archaeological, and Linguistic Data. Proceedings of the National Academy of Sciences 85: 6002-6006.

Coe, Kathryn y Craig T. Palmer. 2005. Human Categories and Health: The Power of the Concept of Ethnicity. En Fundamentals of Cancer Prevention, editado por David S. Alberts y Lisa M. Hess, 85-104. Berlín: Springer.

Coimbra, Carlos, Ricardo Ventura Santos y Ana Lúcia Escobar (organizadores). 2003. Epidemiologia e saúde dos povos indígenas no Brasil. Río de Janeiro: Fiocruz-Abrasco,

Comisión Nacional para el Desarrollo de los Pueblos Indígenas y Programa de Naciones Unidas para el Desarrollo (CDI/PNUD). 2006. Informe sobre desarrollo humano de los pueblos indígenas de México 2006. México: CDI/PNUD.

Consejo Nacional de Población (CONAPO). 2001. Tamaño de la población indígena mexicana. En La población de México en el nuevo siglo, editado por CONAPO, 165-180. México: CONAPO. 
De la Vega, Sergio. 2001. Índice de desarrollo social de los pueblos indígenas México: INIPNUD.

Díaz Romo, Patricia y Samuel Salinas Álvarez. 2002. Plaguicidas, tabaco y salud: el caso de los jornaleros huicholes, jornaleros mestizos y ejidatarios en Nayarit, México. Proyecto Huicholes y Plaguicidas. http://www. huicholesyplaguicidas.org/huichol_cas/cont/publi.html (8 de agosto de 2007).

Espinosa Damián, Gisela. 2003. Informe Mortalidad Materna. http://www. laneta.apc.org/kinal/informe.html (3 de septiembre de 2007)

Fernández Ham, Patricia. 1993. La mortalidad infantil indígena en 1990: una estimación a través de municipios predominantemente indígenas. México: Centro de Estudios en Población y Salud.

, Alejandro Tuirán Gutiérrez, Manuel Ordorica Mellado, Guadalupe Salas y Villagómez, Rosa María Camarena Córdova y Enrique Serrano Carreto. 2006. Informe sobre desarrollo humano de los pueblos indígenas de México 2006. México: Comisión Nacional para el Desarrollo de los Pueblos Indígenas y Programa de Naciones Unidas para el Desarrollo.

Fleuriet, K. Jill. 2003. Health and Health Care Problems among the Kumiai of San Antonio Necua and their Indigenous Relatives in Baja California. Reflections of Poverty, Marginality, and a History of Colonization. Californian Journal of Health Promotion 1 (1): 140-157.

Freyermuth, Graciela. 2003. Las mujeres de humo. Morir en Chenalhó. Género, etnia y generación, factores constitutivos del riesgo durante la maternidad. México: CIESAS-INMComité por una Maternidad Voluntaria y sin Riesgos en Chiapas.

Garduño, Everardo. 2001. De comunidades inventadas a comunidades invisibles: hacia un marco teórico para el estudio de los yumanos de Baja California. Estudios Fronterizos 2 (4): 19-48.

Gómez Zavala, Eduwiges. 2005. Sistema de salud comcáac (seri): Ecología política e hibridación social. Tesis de maestría, Centro de Investigación en Alimentación y Desarrollo, A. C.

Gordon, Raymond G., Jr. (editor). 2005. Ethnologue: Languages of theWorld. Dallas: Summer Institute of Linguistics International. http://www.ethnologue.com/. (12 de febrero de 2008). 
Gravlee, Clarence. 2005. Ethnic Classification in Southeastern Puerto Rico: The Cultural Model of “Color”. Social Forces 83 (3): 949-970.

y Elizabeth Sweet. 2008. Race, Ethnicity, and Racism in Medical Anthropology, 1977-2002. Medical Anthropology Quarterly 22 (1): en prensa. http://gravlee.org/gravlee-sweet-preprint.pdf (9 de febrero, 2008)

Guevara, Yolanda, Irene de Haro, Margarita Cabrera, Guadalupe García de la Torre y Paz M. Salazar-Schettino. 2003. Enteroparasitosis en poblaciones indígenas y mestizas de la Sierra de Nayarit, México. Parasitología Latinoamericana 58 (1-2): 30-34.

Guzmán Mejía, Rafael (coordinador). 2004. Disco compacto Etnografía del pueblo huichol.Rasgos biofísicos, socioculturales y de sistemas productivos para el reordenamiento territorial de la nación wixarika, editado por la Comisión Nacional para el Desarrollo de los Pueblos Indígenas-Universidad de Colima.

Haro Encinas, Jesús Armando. 2004. Impactos neo-coloniales: la salud de los pueblos indígenas en Sonora y Arizona. Horizontes. Revista de encuentro entre Sonora y Arizona 9 (18): 12-18.

1981. Burapaco. Estudio de una comunidad de la región guarijía del sur de Sonora. Unidad Médica Rural 3 ImSS-COPLAMAR, Álamos, Sonora. (Mecanografiado).

(coordinador), Blanca E. Lara, María R. Palacios, Vidal Salazar, Patricia Salido et al. 1998. El sistema local de salud guarijío-makurawe. Un modelo para construir. Hermosillo: El Colegio de Sonora-CIAD-Conaculta-UnisonINI.

Hedrick, Basil C., Charles Kelley y Carroll Riley (editores). 1974. The Mesoamerican Southwest Readings in Archaeology, Ethnohistory, and Ethnology. Carbondale: Southern Illinois University Press.

Hersch, Paul y Jesús Armando Haro. 2007. ¿Epidemiología sociocultural o antropología médica? Algunos ejes para un debate interdisciplinar. Conferencia de clausura presentada en el VII Coloquio de REDAM: Etnografías y técnicas cualitativas en investigación sociosanitaria. Un debate pendiente, Tarragona. 6 de junio (en prensa).

Hinds, David A., Laura L. Stuve, Geoffrey B. Nilsen, Eran Halperin, Eleazar Eskin, Dennis G. Ballinger, Kelly A. Frazer y David R. Cox. 2005. Whole- 
Genome Patterns of Common DNA Variation in Three Human Populations. Science 307: 1072-1079.

Hope, Margarita. 2006. Pimas. México: Comisión Nacional para el Desarrollo de los Pueblos Indígenas-PNUD.

Hrdlicka, Ales. 1908. Physiological and Medical Observations among the Indians of Southwestern United States and Northern Mexico. Smithsonian Institution Bureau of American Ethnology Bulletin 34.

Instituto Nacional de Estadística, Geografía e Informática (INEGI). 2001. Resultados definitivos. XII Censo General de Población y Vivienda. México: INEGI.

Instituto Nacional de Lenguas Indígenas (INALI). 2005. Catálogo de lenguas indígenas mexicanas: Cartografía contemporánea de sus asentamientos históricos México: INALI. http://www.inali.gob.mx/catalogo2007/ (12 de febrero de 2008).

Instituto Nacional de Salud Pública (INSP). Encuesta Nacional de Salud y Nutrición 2006. México: INSP. http://www.insp.mx/ensanut/ensanut2006.pdf (12 de septiembre de 2007)

Instituto Nacional Indigenista (INI). 2001. Programa Nacional para el Desarrollo de los Pueblos Indígenas 2001-2006. México: INI.

Janssen, Eric y Regina Martínez. 2006. Una propuesta para estimar la población indígena en México a partir de los datos censales. Estudios Demográficos y Urbanos 21 (2): 457-471.

Jardón, Ana María Victoria. 2004. 500 años de salud indígena. México: Miguel Ángel Porrúa.

Kato, P. 1996. On Nothing and Everything: The Relationship between Ethnicity and Health. En Handbook of Diversity Issues in Health Psychology, editado por P. Kato y T. Mann, 287-300. Nueva York: Plenum Press.

Krieger, Nancy (editora). 2004. Embodying Inequality: Epidemiologic Perspectives. Amityville: Baywood.

2000. Discrimination and Health. En Social Epidemiology, editado por Lisa Berkman e Ichiro Kawachi, 36-75. Oxford: Oxford University Press. 
LaVeist, Thomas A. (editor). 2002. Race, Ethnicity and Health. A Public Health Reader. San Francisco: Jossey-Bass.

1996. Why We Should Continue to Study Race...but Do a Better Job: An Essay on Race, Racism and Health. Ethnicity \& Disease 6 (1-2): 21 29.

Lee, Sandra S.J., Joanna Mountain y Barbara A. Koenig. 2001. The Meanings of "Race" in the New Genomics: Implications for Health Disparities Research. Yale Journal of Health Policy, Law and Ethics I: 33-75.

León Portilla, Miguel. 1972. The Norteño Variety of Mexican Culture: An Ethnohistorical Approach. En Plural Society in the Southwest, editado por Edward H. Spicer y Raymond H. Thompson Spicer, 109-114. Nueva York: Wheaterhead Foundation,

Lewontin, Richard C. 1972. The Apportionment of Human Diversity. Evolutionary Biology 6: 381-398.

Luna Escalante, Gustavo. 2007. Derechos, usos y gestión del agua en territorio yaqui. Tesina de la especialidad en Gestión Integrada de Cuencas Hidrológicas, El Colegio de Sonora.

Luque Agraz, Diana y Antonio Robles Torres. 2006. Naturalezas, saberes y territorios comcáac (seri). Diversidad cultural y sustentabilidad ambiental México: SEMARNATINE-CIAD.

Macbeth, Helen. 2001. Defining the Ethnic Group: Important and Impossible. En Health and Ethnicity, editado por Helen Macbeth y Prakash Shetty, 10-20, Londres: Taylor \& Francis.

y P. Shetty (editores): 2001. Health and Ethnicity. Londres: Taylor \& Francis.

Machinea, José Luis, Alicia Bárcena y Arturo León (coordinadores). 2005. Objetivos de desarrollo del milenio. Una mirada desde América Latina y el Caribe. Washington: OPS.

Matías Alonso, Marcos. 2005. La inclusión del tema indígena en los instrumentos censales. Notas para la reflexión. Ponencia presentada en el Seminario Internacional Pueblos Indígenas y Afrodescendientes de Amé- 
rica Latina y el Caribe: Relevancia y pertinencia de la información sociodemográfica para políticas y programas. Santiago de Chile, 27 a 29 de abril.

Menéndez, Eduardo L. 2002. La parte negada de la cultura. Relativismo, diferencias y racismo. Barcelona: Bellaterra.

2000. Factores culturales. De las definiciones a los usos específicos. En Medicina y cultura. Estudios entre la antropología y la medicina, editado por Enrique Perdiguero y Josep M. Comelles, 163-188. Barcelona: Bellatera.

1990. Antropología médica en México. Hacia la construcción de una epidemiología sociocultural. En Antropología médica. Orientaciones, desigualdades y transacciones. México: CIESAS (Cuadernos de la Casa Chata 179).

Moore, Laurence. 1954. The Continuing Search for a Southwest. Arizona and theWest 6 (4): 275-287.

Mrela, Christopher y Trentham Coe. 2002. Differences in the Health Status among Ethnic Groups, Arizona 2001. Arizona Departament of Health Services-Indian Health Service. http://www.hs.state.az.us/plan (6 de noviembre de 2007).

Mull, Dorothy y Dennis Mull. 1985. Differential Use of a Clinic by Tarahumara Indians and Mestizos in the Mexican Sierra Madre. Medical Anthropology 9 (3): 245-264.

New England Journal of Medicine/Editorial. 2001. Racial Profiling in Medical Research. New England Journal of Medicine 18 (344): 1392-1393.

Parra, Germán. 1950. Densidad de la población que habla lengua indígena en la república mexicana, por entidades federativas y municipios conforme al censo de 1940. En Memorias del Instituto Nacional Indigenista. México: Instituto Nacional Indigenista.

Parry, John H. 1972. Plural Society in the Southwest. An Historical Comment. En Plural Society in the Southwest, editado por Edward H. Spicer y Raymond H.Thompson, 299-320. Nueva York: Wheaterhead Foundation.

Programa de las Naciones Unidas para el Desarrollo (PNUD)-México. 2007. Nota técnica. Cálculo del índice de salud a nivel municipal. http://saul. 
nueve.com.mx/competividad/images/nota\%20tecnica\%20SALUD.pdf (14 de agosto de 2007).

Relethford, John H. 1994. Craniometric Variation among Modern Human Populations. American Journal of Physical Anthropology 95: 53-62.

Riley, Michael J. 1994. Constituing the Southwest. Contesting the Southwest. Re-inventing the Southwest. Journal of the Southwest 36 (3): 221-241.

Sariego, Juan Luis. 2002. Propuestas y reflexiones para una antropología del norte de México. En La antropología social en el México del milenio. Búsquedas, encuentros y transiciones, editado por Guillermo de la Peña y Luis Vásquez, 373389. México: INI-CONACULTA-FCE.

Scheper-Hughes, Nancy. 1997. La muerte sin llanto.Violencia y vida cotidiana en Brasil. Barcelona: Ariel.

Schulz, Leslie O., Peter H. Bennett, Eric Ravussin, Judith R. Kidd, Kenneth K. Kidd, Julian Esparza y Mauro Valencia. 2006. Effects of Traditional and Western Environments on Prevalence of Type 2 Diabetes in Pima Indians in Mexico and the USA. Diabetes Care 29 (8): 1866-1871.

Secretaría de Salud. 2001a. Salud y nutrición para los pueblos indígenas. México: Secretaría de Salud. Salud.

Sepúlveda, Jaime (coordinador). 1993. La salud de los pueblos indígenas en México. México: Instituto Nacional Indigenista-Secretaría de Salud.

Sheldon, Trevor A. e Hilda Parker. 1992. Race and Ethnicity in Health Research. Journal of Public Health Medicine 14 (2): 104-110.

Simonelli, Jean. 1987. Defective Modernization and Health in Mexico. Social Science and Medicine 21 (1): 23-26.

Smith, Anthony D. 1997. La identidad nacional. Madrid: Trama Editorial.

Spicer, Edward H. 1962. Cycles of Conquest. The Impact of Spain, Mexico, and The United States on the Indians of the Southwest, 1533-1960. Tucson: University of Arizona Press. 
Torres, José Luis, Renata Villoro, Teresita Ramírez, Beatriz Zurita, Patricia Hernández, Rafael Lozano y Francisco Franco. 2003. La salud de la población indígena en México. En Caleidoscopio de la salud. De la investigación a las políticas y de las políticas a la acción, editado por Funsalud, 41-55. México: Funsalud.

Valencia, Mauro E., Peter H. Bennett, Eric Ravussin, Julián Esparza, Caroline Fox y Leslie O. Schulz. 1999. The Pima Indians in Sonora, Mexico. Nutrition Reviews 57 (5 II): S55-S58.

Whitehead, Margaret. 2000. The Concepts and Principles of Equity and Health. Copenhagen: World Health Organization, Regional Office for Europe.

Young, T. Kue. 1994. The Health of Native Americans. Towards a Biocultural Epidemiology. New York-Oxford: Oxford University Press.

Zolla, Carlos. 2003. Sobre las relaciones de la medicina tradicional indígena en los sistemas de salud. América Indígena LXI (2): 69-82.

y Emiliano Zolla. 2004. Los pueblos indígenas de México. 100 preguntas. México: UNAM. 
